Journal of Advanced Research in Fluid Mechanics and Thermal Sciences

\title{
Design and Three-Dimensional Simulation of a Solar Dish-Stirling Engine
}

\author{
Sherihan Abd El-Ghafour ${ }^{1,}{ }^{*}$, Nady Mikhael ${ }^{1}$, Mohamed El-Ghandour $^{1}$ \\ 1 Mechanical Power Engineering Department, Faculty of Engineering, Port-Said University, Egypt
}

\begin{tabular}{|c|c|}
\hline ARTICLE INFO & ABSTRACT \\
\hline $\begin{array}{l}\text { Keywords: } \\
\text { Solar Stirling engine; Multi-facet dish } \\
\text { concentrator; Cavity receiver; CFD } \\
\text { simulation }\end{array}$ & $\begin{array}{l}\text { Design and three-dimensional simulation of a solar Dish-Stirling (SDS) engine is } \\
\text { currently performed. The design starts with the GPU-3 Stirling engine, which is } \\
\text { originally built to generate power from the fossil fuel exclusively. The design is } \\
\text { conducted through three subsequent phases. Firstly, several parabolic dishes with } \\
\text { different rim angles and number of facets are investigated to optimally design the dish } \\
\text { concentrator. Secondly, different relative positions of the receiver aperture to the dish } \\
\text { focal plane are tested to reach the optimal position. The optical simulation of the solar } \\
\text { concentration process is carried out using SolTRACE software. Finally, an optimal design } \\
\text { for a cavity receiver that involves a new structure of the heater tubes is performed. The } \\
\text { simulation of the engine with the designed receiver is implemented using the } \\
\text { commercial CFD code ANSYS FLUENT. Having finished the design, a comprehensive } \\
\text { energy analysis of the designed SDS engine is carried out. The results show that a nearly } \\
\text { uniform temperature distribution of the heater tubes throughout the cycle is achieved. } \\
\text { The overall thermal efficiency of the designed SDS engine is about } 31.8 \% \text { at a DNI of } \\
1000 \mathrm{~W} / \mathrm{m}^{2} \text {. }\end{array}$ \\
\hline
\end{tabular}

\section{Introduction}

Fossil fuel still dominates the global energy market. According to the U.S. Energy Information Administration (EIA), fossil fuel supplies $84 \%$ of the world's primary energy [1]. However, the massive shortage of the fossil fuel resources, the fluctuations in fuel prices, and the severe environmental problems due to its combustion inevitably lead to reduce our dependence on this type of energy source. Additionally, due to the continuous growth in world population and modernization, the global energy demands are expected to increase further over the coming years. These considerable issues increase the urgency to widen the use of the renewable energy resources. Solar energy, particularly, has been regarded as a key source for future. Furthermore, for many solar thermal technologies, it is possible to include an effective thermal storage system or a hybrid scheme, with fossil fuels or biomass. This helps to avoid interruptions during transient conditions or after sundown [2]. Accordingly, solar energy is expected to provide about 26 percent of the world electricity demand by 2050 [3].

\footnotetext{
* Corresponding author.

E-mail address: s.a.ghafour@eng.psu.edu.eg
}

https://doi.org/10.37934/arfmts.82.1.5176 
Solar energy technologies for power generation are divided into two main categories: the photovoltaic (PV) and the concentrating solar power (CSP) [4]. The concentrated solar power (CSP) technology incorporates four essential designs; parabolic trough, power tower, linear Fresnel and Dish-Stirling system. The solar Dish-Stirling (SDS) systems are recognized as the most efficient of the existing technologies for the solar-to-electricity conversion. The efficiency of this system reaches nearly $32 \%$ of direct normal incident radiation, compared to around $18 \%$ and $25 \%$ for parabolic trough and power tower designs, respectively $[5,6]$. Along with its high potential efficiency, the SDS system can provide power even at places where scarcity of water is prevailing [7]. Furthermore, the modular nature of this system makes it particularly suitable for small and medium scale solar power plants [8]. Also, individual units can operate independently, off-grid, in remote locations [9]. In this context, it should be mentioned that the high capital, operating and maintenance costs are the main disadvantage of this system. These cost issues are expected to be reduced with mass production and further development of the system [10,11]. The SDS system consists of parabolic dish concentrator, solar-tracker, cavity receiver, Stirling engine and electrical generator, as shown in Figure 1.

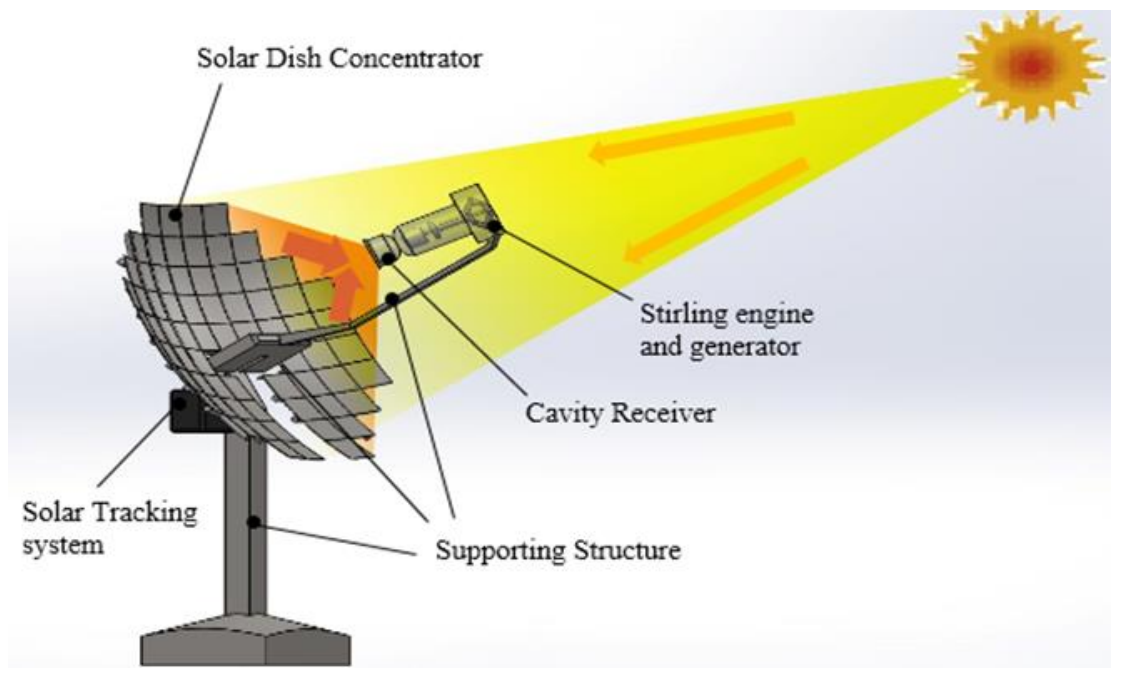

Fig. 1. Schematic diagram of a solar Dish-Stirling system

Currently, the SDS system has becomes the focus of extensive research. Unfortunately, most of the research focuses on each component individually. Indeed, limited studies [12-18] have addressed the whole system and the interactions between its components. Yaqi et al., [12] developed a general analytical model for the maximum output power and its corresponding thermal efficiency. In order to make a neat analysis, they neglected several effects and irreversibilities within the system. Ahmadi et al., [13] extended the work of Yaqi et al., [12], towards simultaneous maximization of the thermal efficiency and the output power by employing multi-objective evolutionary algorithms. Mingzhen and Jinzhong [14] developed a non-linear time-domain model to simulate a commercial SDS System. They covered the entire range of system operation, from start-up to full power conditions. However, they significantly based on simple correlations for estimating the imperfections and the thermal losses. A simple modeling for the components of an unconventional controlled system was later conducted by Beltran-Chacon et al., [15]. More recently, Kadri and Abdallah [16] numerically investigated the feasibility and the performance of a standalone SDS system that hybridized with a permanent magnet synchronous generator and a storage battery. Their model was based on a simple classical approach of Stirling engine analysis.

Here, it is worth mentioning that the above studies assumed a uniform temperature distribution on the absorber (heater) surface rather than the expected nonuniform one. This nonuniform 
distribution is resulted from the uneven distribution of the concentrated radiation flux on the receiver aperture. The results under this assumption may be dramatically far from the reality. In this context, a global thermal model of the energy conversion of a $10 \mathrm{kWe}$ Eurodish SDS system were presented by Nepveu et al., [17]. This model is one of the first models that considered the nonuniform distribution of the concentrated radiation flux on the receiver aperture. Also, they took into consideration all types of thermal losses of the receiver. However, they simplified the Stirling engine modeling with several assumptions besides neglecting the different types of losses except the pumping loss. Later, Barreto and Canhoto [8] developed a global model of a small-scale SDS system. In their model, the ray tracing technique was used to determine the radiation flux distribution on the receiver opening. A detailed thermal model for the receiver was also developed. In addition, two submodels for the thermal cycle and the mechanical to electrical energy conversion were integrated to the concentrator and receiver models. However, they conducted a simple design for all system components and applied several simplifications throughout the modelling. In an attempt to implement a high-performance commercial unit, Yan et al., [18] designed and experimentally tested a $38 \mathrm{~kW}$ SDS system. They started with a mature $\alpha$-type, four cylinders and double-acting Stirling engine, namely S260. A cavity receiver with a secondary reflector was designed and integrated to this engine. The results showed that this system could achieve a solar-to-electricity conversion efficiency of about $26 \%$ with a DNI at $750 \mathrm{~W} / \mathrm{m} 2$.

Based on the above literature survey, two important issues are noticed. The first is related to the design and the second is about the analysis technique. Regarding the design, most of the previous work was conducted on specific designs of the SDS system. These are either commercial units or simple designs proposed by researchers. Unfortunately, the existing commercial units are limited and most of its design and operating specifications are not easily available. Regarding the analysis technique, most of the Stirling engine modeling techniques that are integrated to the whole system modeling, are relatively simple. They are usually accompanied by several assumptions and neglecting most of the engine losses. Consequently, these might cause a high degree of inaccuracy in the performance predictions of the whole SDS system. According to these issues, the current study is intended to design and analyze a high-performance SDS engine using the CFD approach. Recently, the Computational Fluid Dynamics (CFD) models have achieved high accurate predictions of the Stirling engine performance [19-21]. In this study, a mature Stirling engine, namely the Ground Power Unit (GPU-3), is selected to be the base of the current design of the solar engine. As it is one of the most famous, well-documented as well as high-performance $\beta$-type Stirling engine with the rhombic drive mechanism. Also, the advantageous characteristics of the $\beta$-type configuration integrated with the rhombic drive mechanism make it more convenient for solar applications [22]. However, the conventional shape of the heater tubes arrangement in the case of $\beta$-configuration is not basically suitable for receipting the solar energy. Therefore, the choice of a $\beta$-type engine should be followed by a new design for the heater pipes. This engine was originally designed to generate power from the fossil fuels exclusively [23]. Hence, an optimal design for a cavity receiver that involves the new structure of the heater tubes is conducted to replace the original heater of the GPU-3. The optimal design of the receiver is identified according to the best compromise among three fundamental aspects. These are the uniform irradiance distribution on the receiver and absorber walls, high optical absorption efficiency as well as low pumping loss. Furthermore, a complete design of a suitable dish concentrator is performed. Herein, the design of the dish is optimized to achieve a high optical concentration ratio along with a high degree of uniformity for irradiance distribution on the receiver aperture. The design specifications of the GPU-3 engine have been documented by El-Ghafour et al., $[19,20]$. In the following subsections, the design phases, the simulation methodology and the CFD results of the SDS engine are reported. 


\section{Setting Aperture Diameter of Parabolic Dish Concentrator and Cavity Receiver}

The design of the SDS system is usually started with the selection of two main dimensions. These are the aperture diameters of the dish concentrator, $D_{\text {con, }}$ and the cavity receiver, $D_{\text {rec. }}$. As the suitable identification of these dimensions can achieve the desired concentration ratio. The size of the dish concentrator depends mainly on the peak electrical power system ( $\left.P_{\text {elect }}\right)$, the maximum direct normal irradiance (DNI) and the efficiency of solar-to-electrical energy conversion as follows $[7,24]$

$\mathrm{P}_{\text {elect }}=\mathrm{A}_{\mathrm{con}} \cdot \mathrm{DNI} \cdot \eta_{\mathrm{ov}}$

$D_{\text {con }}=\sqrt{\frac{4}{\pi} \cdot A_{\text {con }}}$

where $A_{c o n}$ is the aperture area of the concentrator and $\eta_{\text {ov }}$ is the overall efficiency of the SDS system. In the current study, a DNI of $1000 \mathrm{~W} / \mathrm{m} 2$ is selected. The peak electrical power from the GPU-3 Stirling engine is about $8.5 \mathrm{~kW}$. The typical SDS system efficiency varies from 17 to $30 \%$. Hence, the initial efficiency can be assumed as $24 \%$. Accordingly, the aperture diameter of the dish can be taken as $7.0 \mathrm{~m}$.

The identification of the receiver aperture diameter is currently governed by a trade-off between two aspects. The first one is to increase the diameter to capture most of the concentrated irradiation. While, the second one is to restrict this increase in order to achieve the standard shape of the cavity receiver and to avoid severe modifications on the original dimensions of the engine. Accordingly, the aperture diameter of the receiver is selected to be $14.0 \mathrm{~cm}$. One of the most important parameters used in assessing the optical performance of the solar concentration process is the concentration ratio. Two different definitions of the concentration ratio are used in general. These are the geometric and the optical concentration ratios. The geometric concentration ratio, $\mathrm{CR}_{\mathrm{g}}$, is defined as the ratio of the concentrator aperture area $\left(A_{c o n}\right)$ to the receiver aperture area $\left(A_{\text {rec }}\right)[25]$. According to the proposed dimensions, $\mathrm{CR}_{\mathrm{g}}$ is about 2500. This ratio ranges from 1000 to 3200 for the current commercial units. Here, it should be pointed out that the effect of the shaded area on the concentration process is neglected. Generally, the shading error is kept less than $1 \%$ if the dish aperture size is much larger than that of the receiver. As clarified, the proposed diameters for the dish and receivers makes this assumption reasonable.

\section{Optical Design and Simulation of Parabolic Dish Concentrator}

Practically, the parabolic concentrator can either consist of single large continuous surface or an assembly of several smaller surfaces, usually referred to as multi-facet construction [22]. In the multifacet construction, the technical difficulties of production, handling and maintenance and the high costs, accompanied with the continuous surface dishes, are significantly avoided [7]. Besides, the multi-facet construction effectively operates in the windy climate [18]. More importantly, the multifacet concentrator has another advantage over the continuous surface one in that the heat flux distribution on the receiver opening is more uniform. Consequently, the local overheating damage is avoided, and the engine lifespan is significantly increased [26]. Furthermore, the heater is subjected to a more uniform temperature distribution approximately approaching the isothermal distribution. Hence, the engine may achieve a higher thermal efficiency. 
In the current study, the multi-facet space frame parabolic dish type is selected as concentrator in the design. This is attributed to its simplicity in design and implementation compared with the stretched membrane parabolic dish type. More importantly, there are barely gaps between the facets of this design, which lead consequently to utilize the whole concentration area. The losses due to these gaps may reach approximately $36 \%$ for the stretched membrane type [27]. In the following subsections, the methodology of the optical simulation and the optimal design phases of the multifacet parabolic dish are presented.

\subsection{Methodology of Optical Simulation}

The optical simulation of the solar concentration process is carried out using the open source software SoITRACE based on Monte-Carlo ray-tracing technique. The simulation is limited to the dish and the receiver aperture. This receiver aperture is represented as a circular surface with specific diameter for receiving the concentrated irradiance.

\subsubsection{CAD geometry}

The simulation firstly requires a creation of the geometrical model of the dish concentrator. Firstly, a drawing of the parabola which represents the base of the dish design is created. A publicdomain software, Parabola Calculator 2.0, is currently used for calculating the $x$ and $y$ coordinates of the defining points of the parabola.

Then, the ideal parabolic dish by a 3D computer-aided design (CAD) software SolidWorks is formed. Here, each facet is designed as a square flat mirror. The facets are arranged to approximately form the parabolic shape. However, the assembly of the facets in the parabolic shape with appropriate position and orientation for each facet, so-called facets alignment, has not been an easy task. It is basically related with the number and size of the facets. In the present study, the identification of the facets number and area is based on an optimization algorithm proposed by Pavlovi et al., [28]. Finally, these facets, of specified number and area, are charted using SolidWorks to accurately identify the facets orientation and the coordinates of each vertex. Figure 2 illustrates a 3D CAD model of the multi-flat facet parabolic dish concentrator.

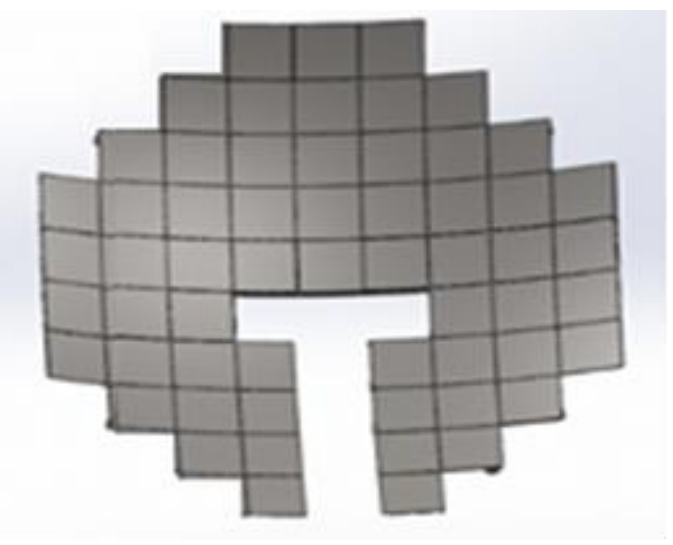

Fig. 2. Three-dimensional CAD model of multi-flat facet parabolic dish 


\subsubsection{Solution scheme}

The first step of the simulation in SolTRACE software is to define the sun as the light source by two characteristics. These are the sun shape and position. A pillbox approximation is considered for the sun shape, with a half-angle of $4.65 \mathrm{mrad}\left(16^{\prime}\right)$. The direction of the sun is defined relative to the global coordinate system. Also, the position of dish concentrator is defined according to the global coordinate system. Whereas, each facet of the multi-facet dish is introduced separately according to its orientation and position within the coordinate system of the dish. The interaction of the rays with the elements is set to be reflective. The optical error in the current simulation ranges from $5-20$ mrad. Here, it should be mentioned that the optical error in the SolTRACE software is only determined by both the slope and specularity errors [29]. Besides, the tracking error ranges from $0-$ $2^{\circ}$ throughout the simulations.

As the Monte-Carlo ray-tracing technique is a stochastic method, its accuracy is dependent on the number of the rays traced. Therefore, the number of rays independency study is performed to ensure that the essential physics is independent of the ray number. Accordingly, three different rays number of 1.5 million, 2.7 million and 3.6 million are tested. With respect to the variation of irradiance flux distribution, the maximum deviation between the medium and small numbers of rays does not exceed $2.5 \%$. Therefore, the number of rays of 2.7 million is adopted for the current study.

\subsection{Validation of Optical Simulation}

The irradiance distribution calculated by SoITRACE software is validated against the experimental results performed by Dunn et al., [30]. The comparison between the results is illustrated in Figure 3 . The default operational condition is listed on the figure. As seen from this figure, the results calculated are in good agreement with the experimental results.

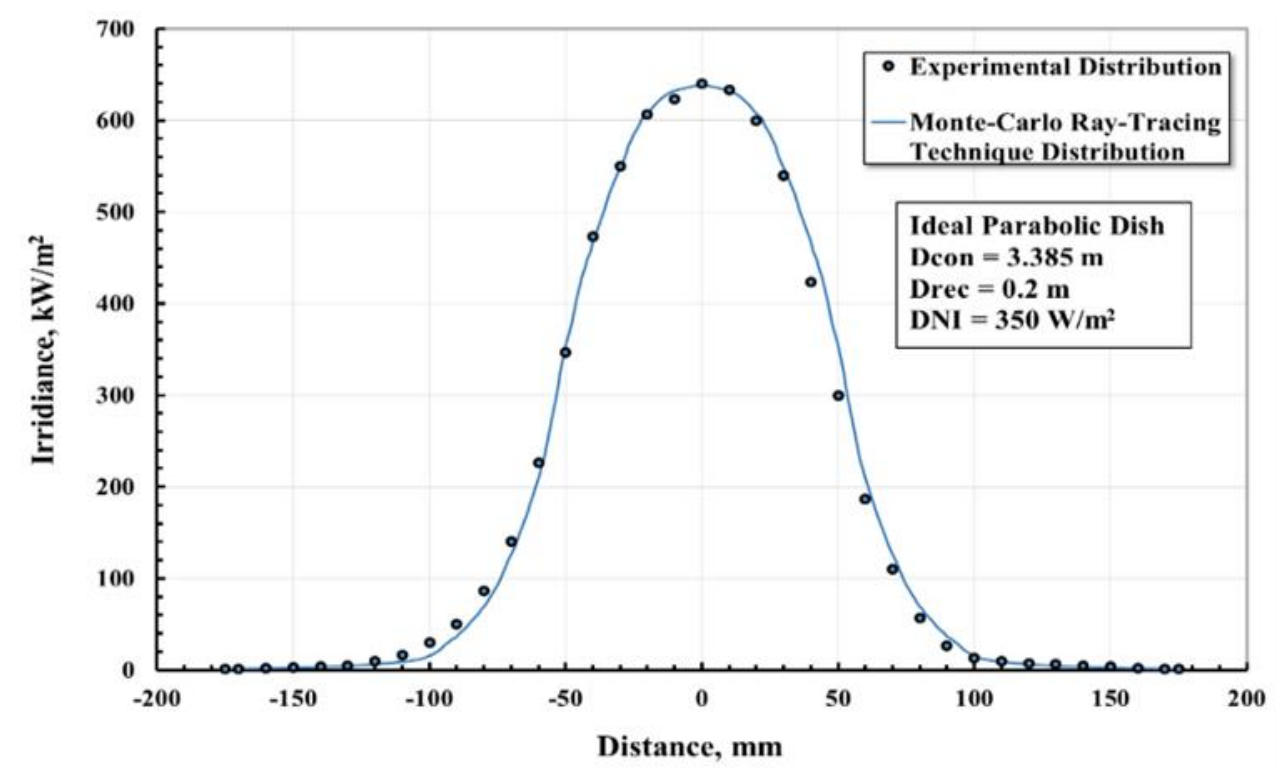

Fig. 3. Comparison of irradiance flux distribution between Monte-Carlo raytracing results and experimental results 


\subsection{Optimal Design of Multi-Facet Parabolic Dish Concentrator}

Generally, the complete design of the multi-facet dish requires, besides the diameter, to identify two other characteristic geometric parameters. These are the rim angle and the number of the facets. Also, the relative position of the receiver aperture with respect to the focal plane is another significant design parameter in the irradiance concentration process. The design phases of the dish start with a specific design, so-called the baseline design. According to this design, the modifications of the three design parameters are executed. For each design phase, the optimal design condition obtained is taken as a reference for the subsequent phases.

\subsubsection{Characterization of the baseline design}

A parabolic dish of single continuous surface with an aperture diameter and rim angle of $7 \mathrm{~m}$ and $38^{\circ}$, respectively, is simulated. The reflectivity of the dish material is set as $94 \%$. The receiver aperture is represented as a circular surface of $14.0 \mathrm{~cm}$ in diameter placed at the focal plane of the dish. The optical simulation with the SoITRACE software for this case is illustrated in Figure 4.

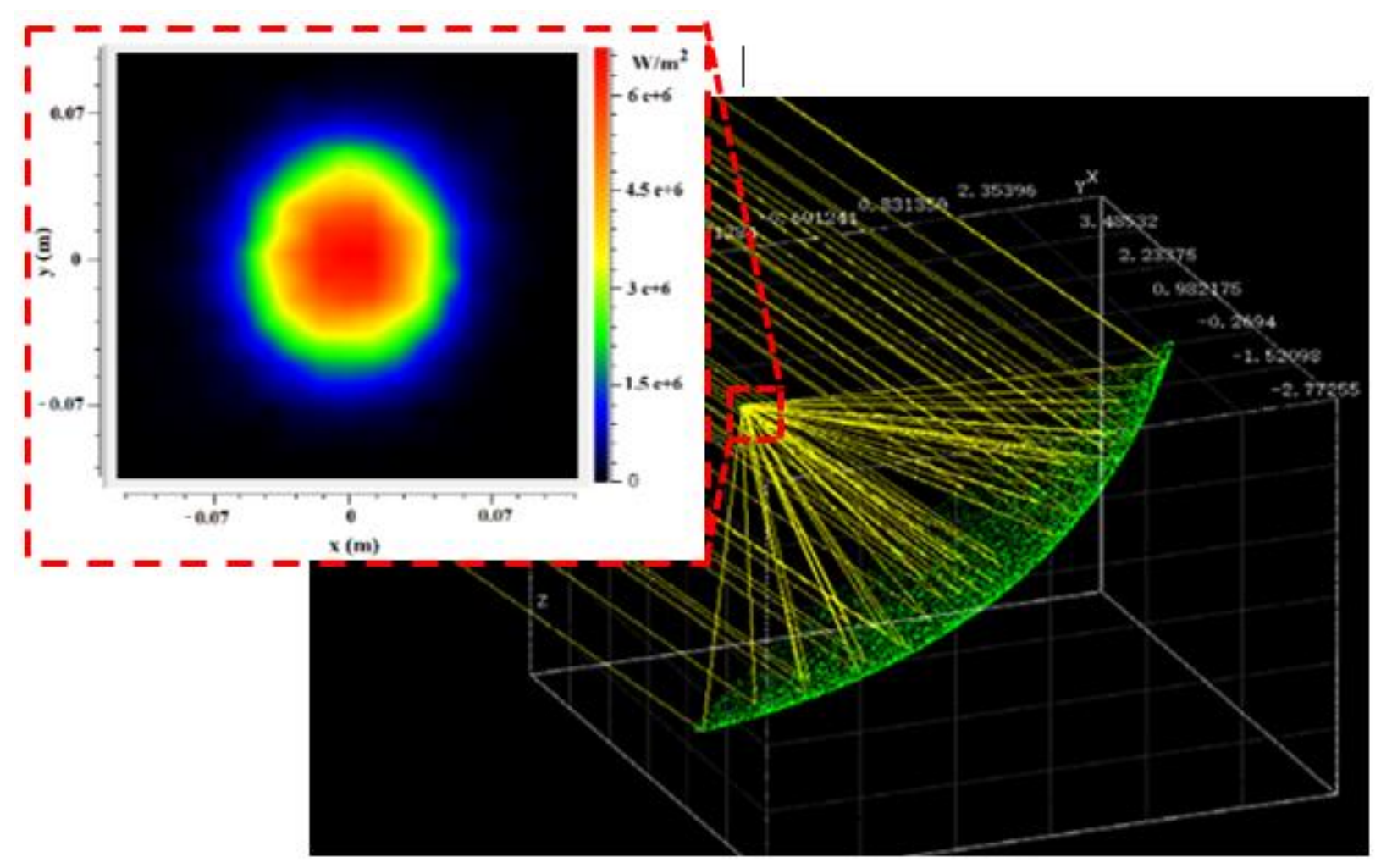

Fig. 4. Ray-tracing simulation of the baseline case using SolTRACE software

Figure 5 maps the contours of the solar irradiance on the receiver aperture of the baseline design. Also, the spatial distribution of the irradiance into the $x$-direction is displayed in this figure. Figures 4 and 5 clearly indicate that the irradiance contours are highly axisymmetric. The region of a peak irradiance, which is usually named the "hot-spot" region, where the flux exceeds $10500 \mathrm{~kW} / \mathrm{m} 2$, is limited to a circular area of radius $0.5 \mathrm{~cm}$. Outside of this region, the flux decreases rapidly at a rate of about $2000 \mathrm{~kW} / \mathrm{m} 2$ per $1 \mathrm{~cm}$ before it gradually faded out. The whole area contoured on the graph is considered as the solar image that is focused by the parabolic dish on the receiver aperture. Moreover, the spatial distribution of the irradiance in any direction is represented as a typical 
Gaussian profile. This type of distribution is classified as a highly non-uniform. For this case the peak irradiance is about $10600 \mathrm{~kW} / \mathrm{m} 2$, while the mean irradiance is around $6730 \mathrm{~kW} / \mathrm{m} 2$. Here, it should be pointed out that the large difference between the peak and mean values of irradiance indicates the weakness of this design.

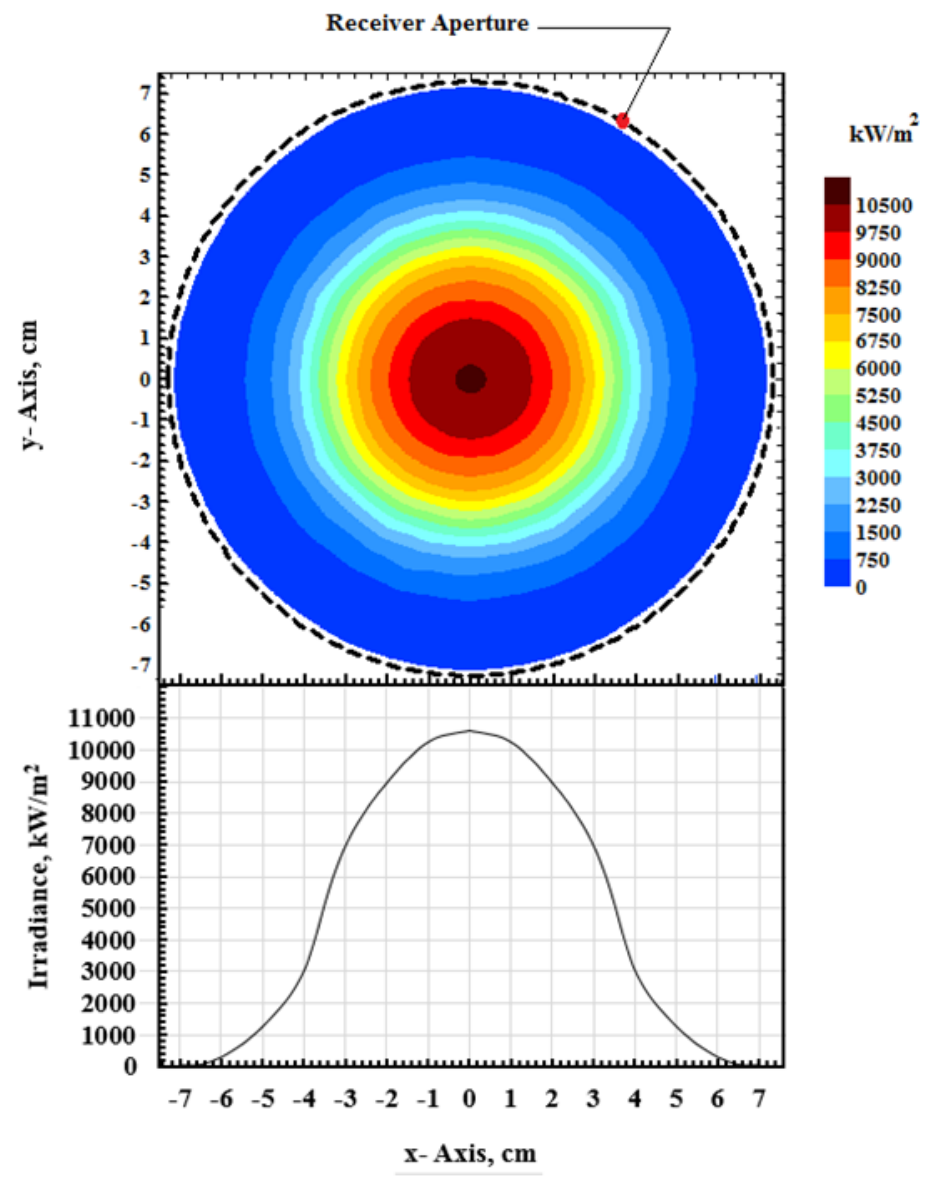

Fig. 5. Map of irradiance contours with spatial distribution of irradiance in the $\mathrm{x}$-direction on the receiver aperture

\subsubsection{Optimization of rim angle of parabolic dish concentrator}

Rim angle is the first characteristic parameter to be studied for optimizing the design of the parabolic dish. The rim angle $\left(\psi_{\text {rim }}\right)$ is defined as the angle between the dish axis and the line between the focal point and the dish rim [22]. This is attributed to its significant impact on the irradiance distribution on the receiver aperture [31,32]. The optimal value of the rim angle is currently identified as the best compromise between two aspects. These aspects are the uniformity of the irradiance distribution and the optical concentration ratio. The optical concentration ratio, $C_{\circ}$, is defined as the averaged irradiance $\left(I_{\text {rec }}\right)$ integrated over the receiver aperture area $\left(A_{\text {rec }}\right)$ divided by the incident irradiance on the concentrator aperture (Icon) [25].

$\mathrm{CR}_{\mathrm{o}}=\frac{\frac{1}{\mathrm{~A}_{\mathrm{rec}}} \int \mathrm{I}_{\mathrm{rec}} \cdot d \mathrm{~A}_{\text {rec }}}{\mathrm{I}_{\text {con }}}$

Here, the diameter ratio of the hot spot to the total solar image is taken as an indication for the degree of irradiance distribution uniformity. The bigger the diameter ratio, the lower the degree of 
the distribution uniformity. The hot spot can be defined as the region in which the normalized irradiance, ratio of the local irradiance to the peak one, is higher than $90 \%$. Figure 6 shows the variation of the hot spot to the solar image diameter ratio and the optical concentration ratio as functions of the rim angle. As illustrated from this figure, a decrease in the diameter ratio of the hot spot to the solar image with increasing rim angle up to a minimum value is firstly observed. This is followed by a slightly increase in the diameter ratio as the rim angle increases. Whereas, a thoroughly different behaviour is observed for the $C_{0}$. A rapid increase in the $C_{0}$ value is initially occurred with increasing the rim angle till reaching to $45^{\circ}$. With any further increase of the rim angle, the $\mathrm{CR}_{0}$ decreases markedly. This is attributed to that the optical concentration ratio is theoretically proportional to the square of $\sin \left(2 \psi_{\text {rim }}\right)$. This also explains the reason of achieving the maximum $\mathrm{CR}_{\circ}$ at the rim angle of $45^{\circ}$ [27]. Regarding these results, the optimal rim angle of the proposed parabolic dish can be identified as $45^{\circ}$.

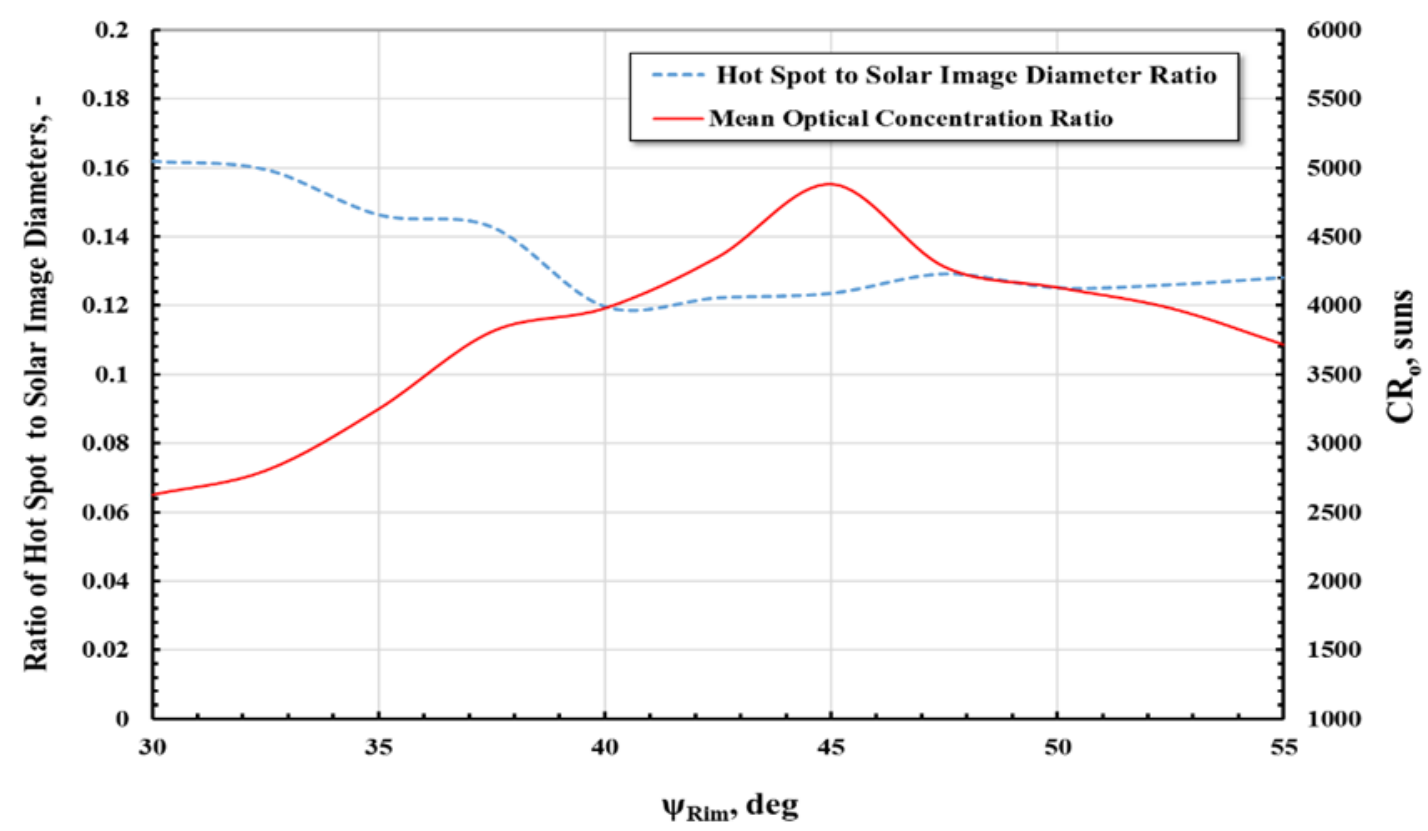

Fig. 6. Variation of hot spot to solar image diameter ratio and optical concentration ratio, as functions of rim angle

\subsubsection{Optimization of number of facets}

Basically, the multi-facet type of the dish concentrators behaves in a different manner than the continuous surface concentrators [33]. This can be proven by mapping the irradiance contours from the multi-facet parabolic dish of 68 facets, as displayed in Figure 7.

When the solar rays normally impinge the aperture of the multi-facet dish concentrator, each facet reflected the rays according to its aim-point. This leads to generate an individual solar image by each facet. The shape of the whole solar image is an integration of the individual solar images. This explains the noticeable difference in the irradiance contour maps between the multi-facet and continuous surface dish concentrators. These differences are the location of the peak irradiance, the degree of the irradiance distribution uniformity as well as the symmetry of the distribution in the spatial directions. With respect to the location of the peak irradiance zone, it is not typically at the center of the receiver aperture like the continuous surface dish. It becomes a relatively annulus zone (relatively displaced from the center toward the borders of the solar image). This is considered the main effect of the multi facets. Furthermore, a more uniform irradiance distribution is observed by 
comparing it with the continuous surface parabolic dish shown in Figure 5 . It is quite obvious that the spatial distribution far from the typical Gaussian profile. This also confirmed by the results of Li et al., [26]. Finally, the irradiance contours are notably asymmetric. This is imputed to the alignment process that usually produces small gaps between the facets along with the non-similarity of the facets arrangement in the $\mathrm{x}$ - and $\mathrm{y}$-directions. In fact, this drawback occurs during the design and implementation steps as well. Here, the spatial irradiance distribution in the $x$-direction is used for the purpose of comparison only. Figure 8 presents the effect of changing the number of facets on the spatial irradiance distribution in $\mathrm{x}$-direction.

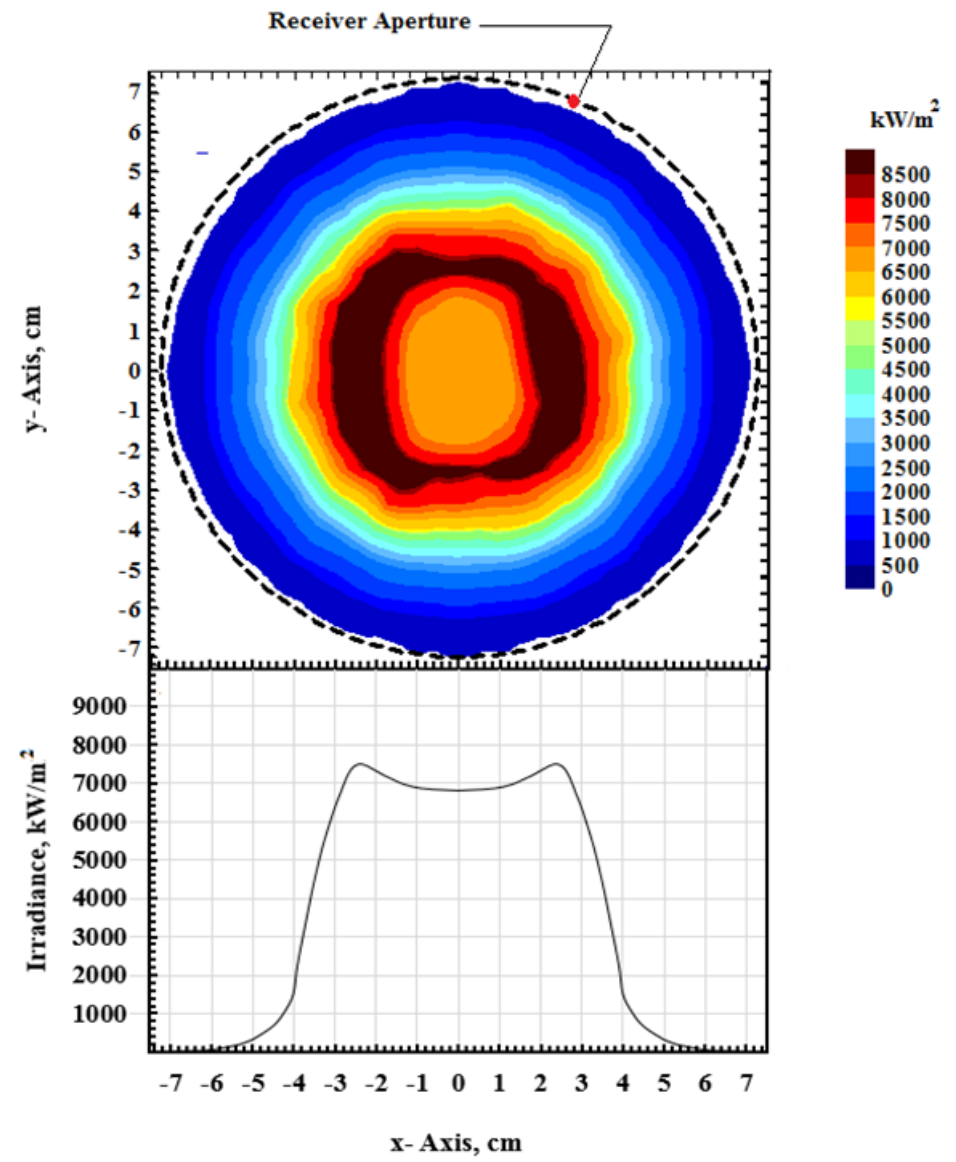

Fig. 7. Map of irradiance contours with spatial distribution of irradiance in the x-direction of multi-facet parabolic dish of 68 facets

As indicated in Figure 8, the increased number of facets leads to a close approximation to the ideal parabolic shape and, consequently, to the Gaussian distribution for the irradiance. As the number of facets is reduced, two contradicting effects are encountered. Firstly, the decrease of the facets number, significantly improves the distribution uniformity, decreases the peak irradiance value and moves the local peak irradiance away from the receiver center. Therefore, the number of facets with a proper alignment can be utilized as a control method for the degree of uniformity and to achieve the local peak irradiance at the desired location. Secondly, the reduction of the facets number causes a remarkable decrease in $\mathrm{CR}_{0}$, as shown in Figure 9. From all these considerations, the number of facets of 68 represents the best compromise between the uniformity of the irradiance distribution and the optical concentration ratio. 


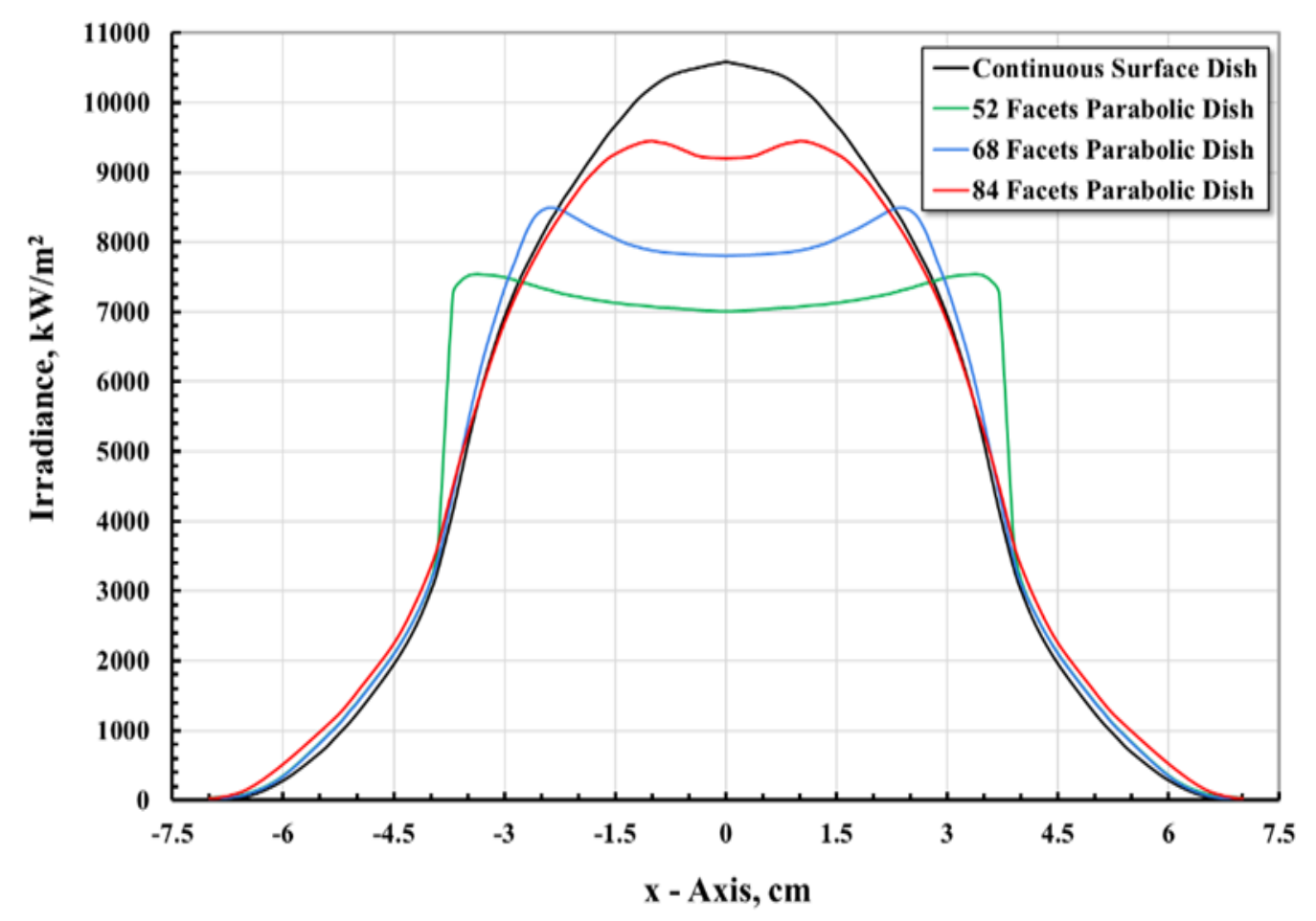

Fig. 8. Spatial irradiance distribution in $x$-direction for multi-facet parabolic dishes with different numbers of facet and continuous surface dish

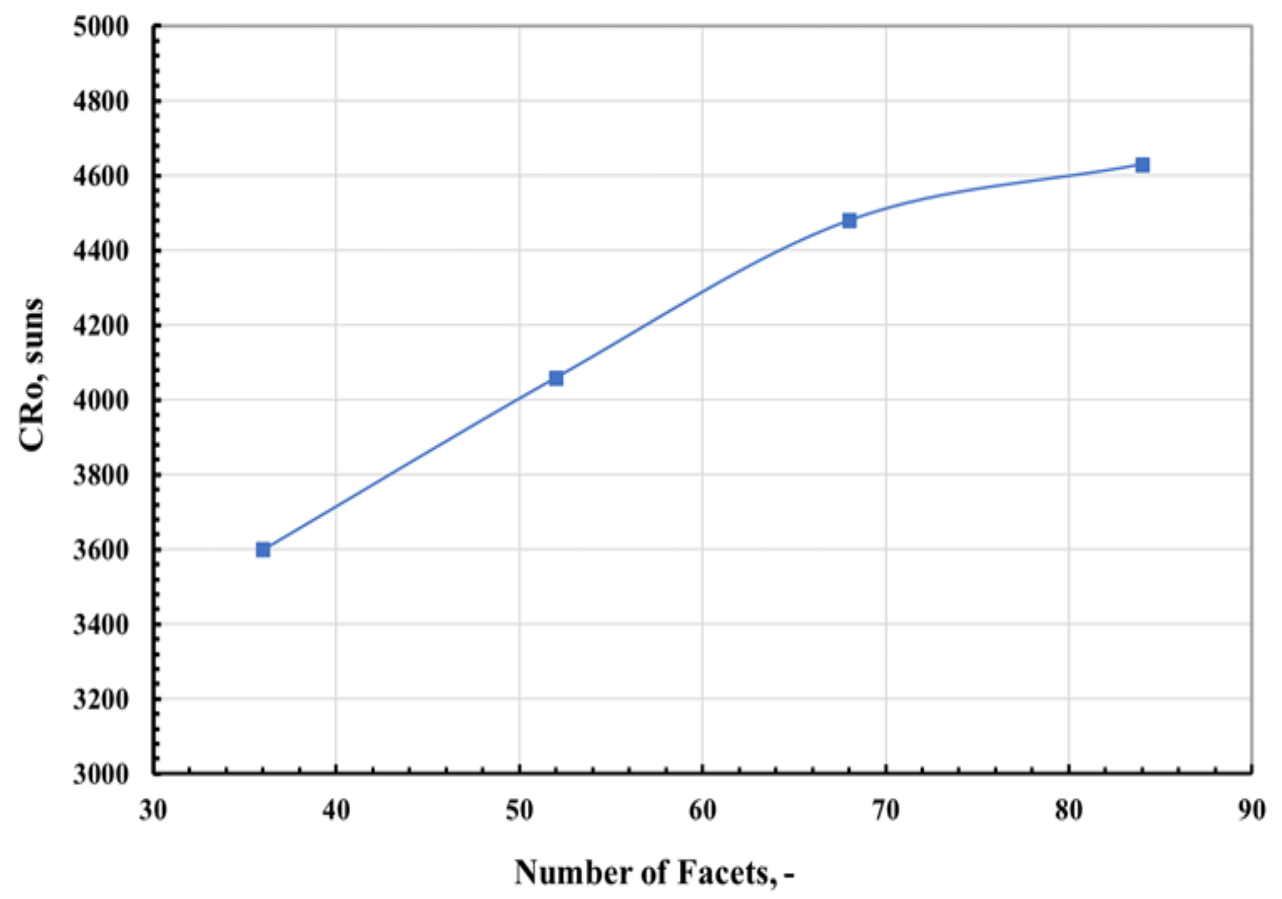

Fig. 9. Variation of optical concentration ratio, as functions of number of facets

\subsubsection{Optimization of relative position of receiver aperture to focal plane of the parabolic dish}

Generally, a conventional method of obtaining a more uniform irradiance distribution is by defocusing the rays by moving the receiver aperture out of the focal plane $[26,34]$. This causes a spread of the solar image on the receiver aperture. Here, there is an allowance for the image spreading, since, the diameter of the image following the preceding modifications is still about 13.25 
$\mathrm{cm}$. It is notably smaller than the diameter of the receiver aperture. Besides, a large part of the receiver aperture is covered by a low irradiance zone, as observed in Figure 7. Meanwhile, the distance of the movement from the focal plane should be limited to avoid a large spillage loss. Figure 10 shows the influence of the relative position of the receiver aperture to the focal plane on the spatial irradiance distribution in the x-direction.

This figure confirms on the more uniformity of the irradiance distribution with the movement of the receiver forward or backward relative to the focal plane. The enlargement of the solar image is also observed. By comparing the three positions, the distribution at the position $\mathrm{C}$ is considered the most uniform; where the plane of the receiver aperture is positioned behind the focal plane. These results are in a well agreement with the results of Li et al., [26]. Certainly, the distribution becomes more uniform when the receiver moves more behind the focal plane. However, this is at the expense of the concentration ratio, as illustrated in Figure 11.

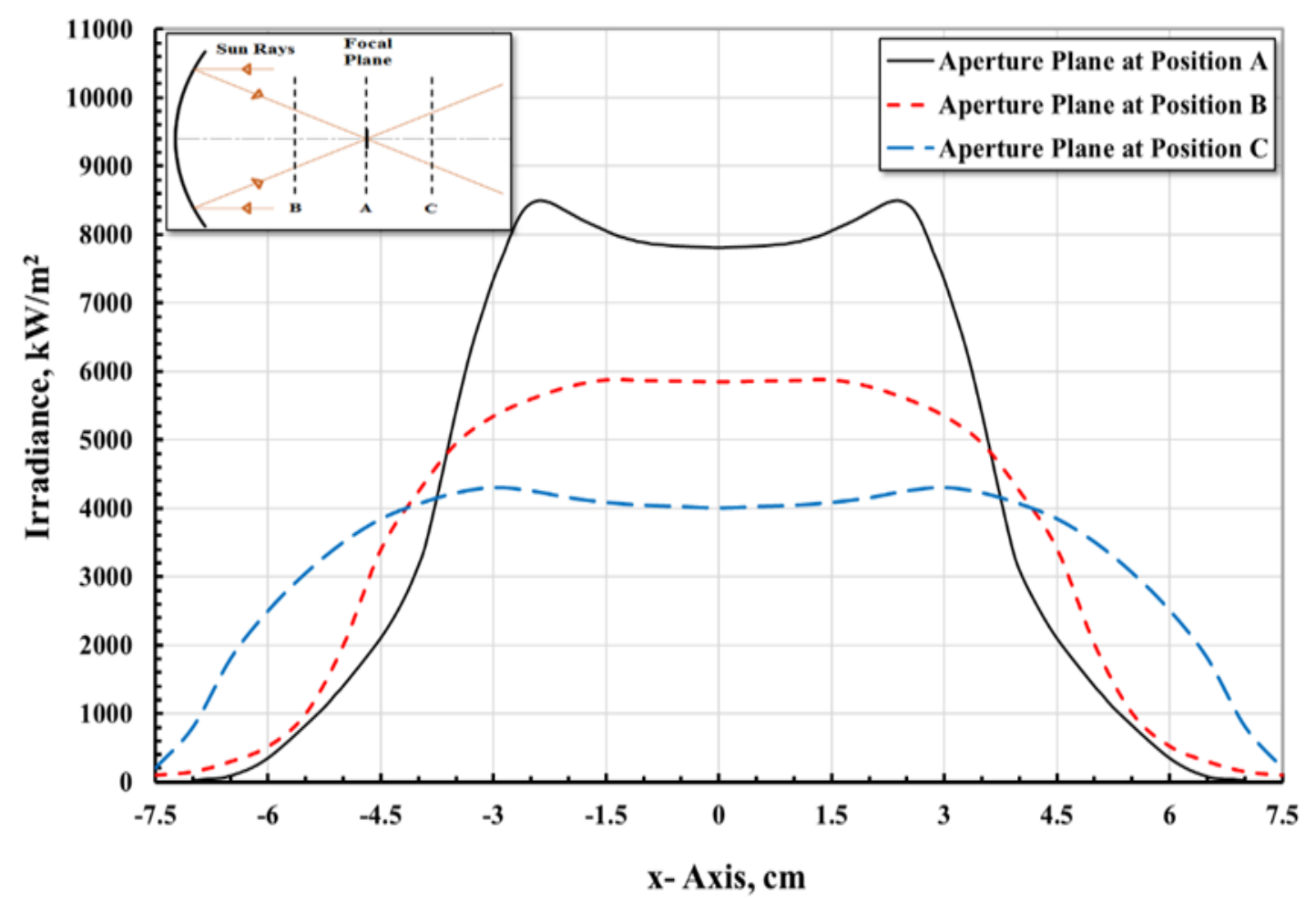

Fig. 10. Influence of relative position of receiver aperture to focal plane on spatial irradiance distribution in $\mathrm{x}$-direction

An expected reduction in the $\mathrm{CR}_{\mathrm{o}}$ is noticed with the movement of the receiver aperture axially behind the focal plane. This reduction starts gradually up to the axial position of $5.4 \mathrm{~cm}$ behind the focal plane. Then this is followed by a sharp reduction for the $C_{\circ}$ o with any increase in the axial distance from the focal plane. Accordingly, the axial position of $5.4 \mathrm{~cm}$ is selected as the optimal position of the receiver aperture plane. This position achieves both a high degree of uniformity for the irradiance distribution and an efficient value for the $C R_{0}$. 


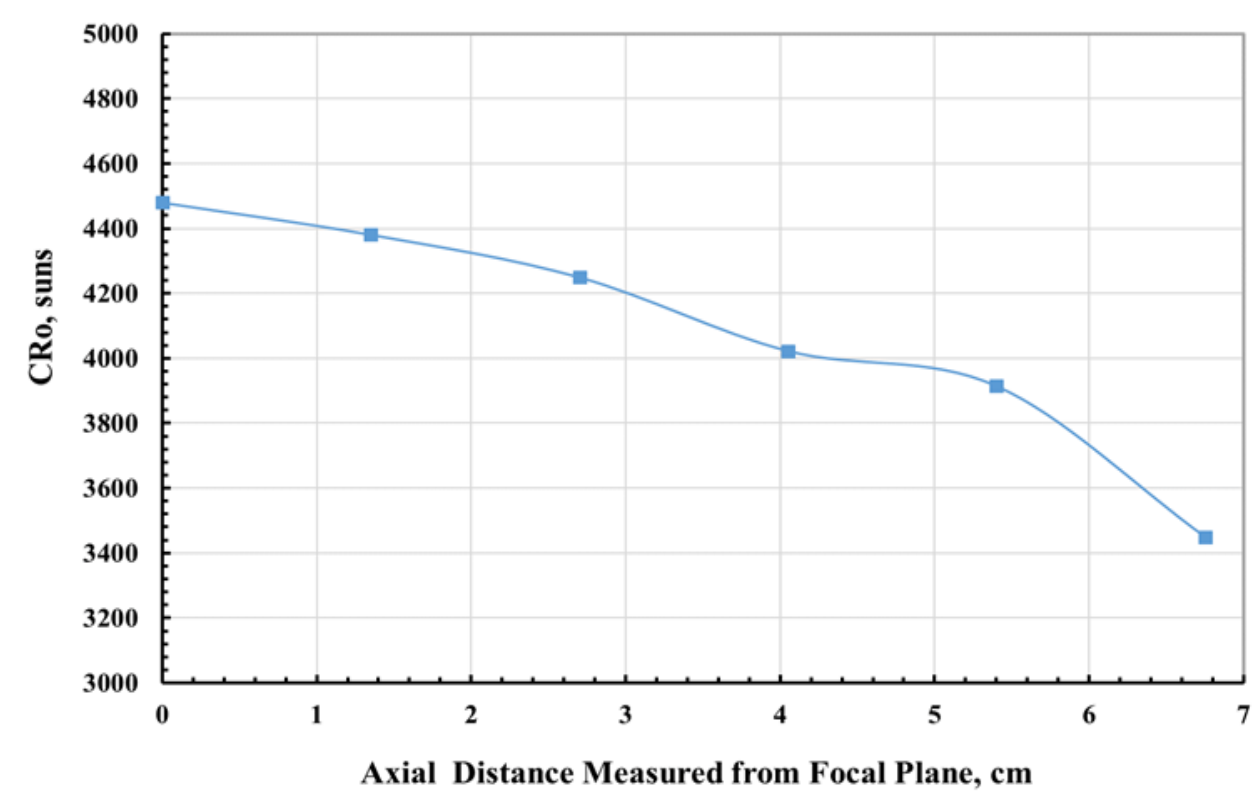

Fig. 11. Variation of optical concentration ratio, as functions of axial distance measured from the focal plane

\section{Design of Cavity Receiver}

The efficient design of the cavity receiver is crucial to a high-performance SDS system. As it couples the dish with the heater (absorber) tubes of the Stirling engine [22]. Generally, the welldesigned receiver homogenizes the heat flux distribution on the heater tubes after multiple reflections and re-absorptions processes that occurs within it [27]. This has been achieved by taking into account some design considerations for the cavity as well as the heater tubes.

Regarding to the cavity receiver, three design characteristics are investigated. These are the cavity shape that achieves a high optical performance, the suitable coating for the inner surface of the receiver cavity and the installation of an effective glass window over the receiver aperture. The identification of the shape is considered as the first step for the cavity receiver design. Among the different shapes of the cavity receivers, the spherical configuration was proved to have the optimal radiance performance [35]. As this configuration achieves the most uniform heat flux distribution on the walls. Therefore, the spherical configuration is selected for the design of the current cavity receiver. Also, it is well known that the heat flux can be more uniformly distributed across the heater tubes by increasing the reflectivity of the inner receiver walls [36]. Therefore, the inner walls of the cavity are coated with a layer of silver of $94 \%$ reflectivity. Furthermore, a fused silica glass is currently used as the aperture cover of the cavity receiver. In fact, this type of glass has a high transmissivity for the solar spectrum [22]. Consequently, it allows for most of the concentrated irradiance entering the receiver. In the same time, it has a low transmissivity for the long wavelength radiation. This, consequently, reduces the radiation loss from the receiver aperture. Besides, the covering of the aperture significantly reduces the natural convection loss from the receiver. With respect to the heater tubes, the effective arrangement of the tubes within the cavity is the first main requirement of the heater design. Whereas, the precise selection of a material of good thermal properties for manufacturing these tubes is the second one. Here, the heater tubes of the base engine design have been rendered to resemble the spherical cavity shape maintaining the same length of the base design tubes. These are aligned with no gaps between the tubes and the inner walls of the cavity. This makes the tubes in a suitable reception mode of the solar irradiance. Moreover, it interacts with the 
radiation exchange that occurs within the cavity. The austenitic stainless steel $253 \mathrm{MA}$ alloy is chosen as a heater tubes material. This is mainly due to its high thermal conductivity and suitability for different manufacturing processes. A thin layer of a high-temperature solar selective coating, silicon nitride (Si3N4), is used for the heater tubes. It decreases the overall reflectivity of the heater tubes [37].

Consequently, the final design of the receiver almost achieves the standard shape of the blackbody cavity. In general, a receiver that resembles the cavity shape and involves heater tubes of high absorptivity along with being covered by a glass window is almost considered as a blackbody cavity. To minimize the conduction and forced convection losses from the receiver, the cavity walls are insulated using a silica-based ceramic material. Also, the cavity is filled with air at atmospheric pressure. Shantia et al., [38] confirmed on the uselessness of utilizing a vacuum pressure within the cavity. As the cost of maintaining this pressure outweighs the benefits of losses reduction.

To complete the design of the receiver, the dimensions of the cavity should be identified. Here, the inner diameter of the cavity is selected to be $17.5 \mathrm{~cm}$. According to this value, the ratio of the aperture diameter to the inner cavity diameter is about $80 \%$. This is a reasonable value to achieve the standard shape of the cavity receiver. As the cavity depth essentially affects the total rate of heat absorbed by the heater tubes [39]. Therefore, three receiver shapes with an inner cavity diameter of $17.5 \mathrm{~cm}$ and different depth are examined by a CFD simulation of the solar Stirling engine. The first one is a hemisphere receiver with a depth of $17.5 \mathrm{~cm}$. The second is a deep-hemisphere receiver with a depth of $19.8 \mathrm{~cm}$. The third is a shallow one with a depth of $14.3 \mathrm{~cm}$. The choice among the proposed shapes of the cavity receiver is based on the optical absorption performance and the pumping loss through the heater tubes. The optical absorption efficiency can be defined as the total heat rate absorbed by the heater tubes divided by the total irradiant power that reached the aperture plane of the cavity receiver. Therefore, a trade-off between the optical performance and the pumping loss should be made to identify the optimal depth. Figure 12 displays the influence of the depth of the hemisphere cavity receiver on the optical absorption efficiency of receiver and the pumping loss through the heater tubes.

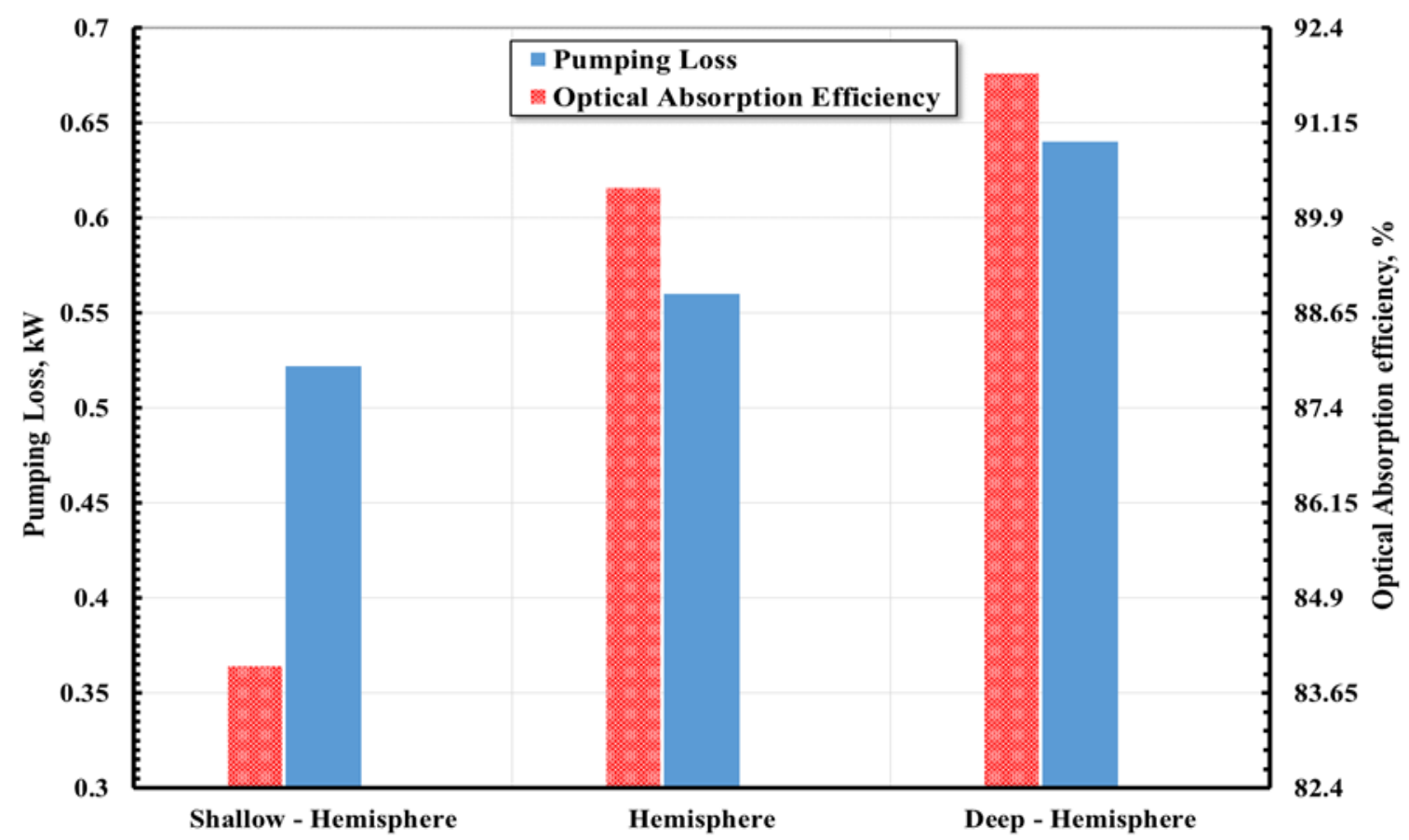

Fig. 12. Influence of depth of hemisphere cavity receiver on optical absorption efficiency of receiver and pumping loss through heater tubes 
As can be illustrated from the figure, the deep-hemisphere cavity receiver achieves the highest optical absorption efficiency. This can be explained by the increase in the multiple reflections and reabsorptions within it compared with the other shapes. Whereas, this shape produces the largest pumping loss among the whole proposed shapes. This is attributed to the additional part in the length of the heater tubes. This makes the shape with the high depth is not usually the best. This contradicts the results of Mao et al., [39] and Li et al., [26]. They affirmed on the superiority of the large depth shapes on the receiver performance. However, they did not unfortunately take into account the effect on the engine power losses. Therefore, an optical absorption rate-to-pumping loss ratio is calculated and used for the trade-off purpose. According to the values of this ratio, the hemisphere cavity shape represents the best compromise between the optical efficiency and the pumping loss.

\section{Final Design Specification and Operating Conditions of SDS Engine}

The final specifications of the multi-facet space frame parabolic dish concentrator and cavity receiver are summarized in Table 1. Figure 13 presents an isometric view of the solar Stirling engine. Table 2 presents the operating conditions applied in the current study.

Table 1

Design specifications of multi-facet parabolic dish concentrator and cavity receiver

\begin{tabular}{ll}
\hline Parameter & Description \\
\hline Number of facets & 68 \\
Area of facets $\left(\mathrm{m}^{2}\right)$ & 40.02 \\
Aperture area of dish $\left(\mathrm{m}^{2}\right)$ & 38.48 \\
Rim angle of dish (deg.) & 45 \\
Material of dish reflective surface (reflectivity) & Silver-coated mirror (94\%) \\
Geometrical concentration ratio (-) & 2500 \\
Optical concentration ratio (-) & 3915 \\
Cavity Receiver shape & Hemisphere \\
Aperture diameter of cavity receiver $(\mathrm{cm})$ & 14.0 \\
Inner diameter of hemisphere cavity $(\mathrm{cm})$ & 17.5 \\
Relative position of receiver aperture to focal & 5.4 \\
plane (cm) & \\
Material of the heater (absorber) tubes & Austenitic stainless steel $253 \mathrm{MA}$ alloy \\
& conductivity at $~ 1000 \mathrm{~K}: 23 \mathrm{~W} / \mathrm{m} . \mathrm{K}$ \\
Selective coating of heater tubes & SisN 4 \\
& Absorptivity at $\sim 900 \mathrm{~K}(\%): 92.6$ \\
Glass cover & Emissivity at $900 \mathrm{~K}: 0.109$ \\
Fluid within cavity & Fused Silica glass of 0.5 cm thickness \\
Pressure within hemisphere (Pa) & transmissivity for solar spectrum (\%): 93 \\
Coating of cavity inner wall & Air \\
\hline & Atmospheric (1.013 x 105) \\
& Silver Reflectivity $(\%): 94$ \\
\hline
\end{tabular}




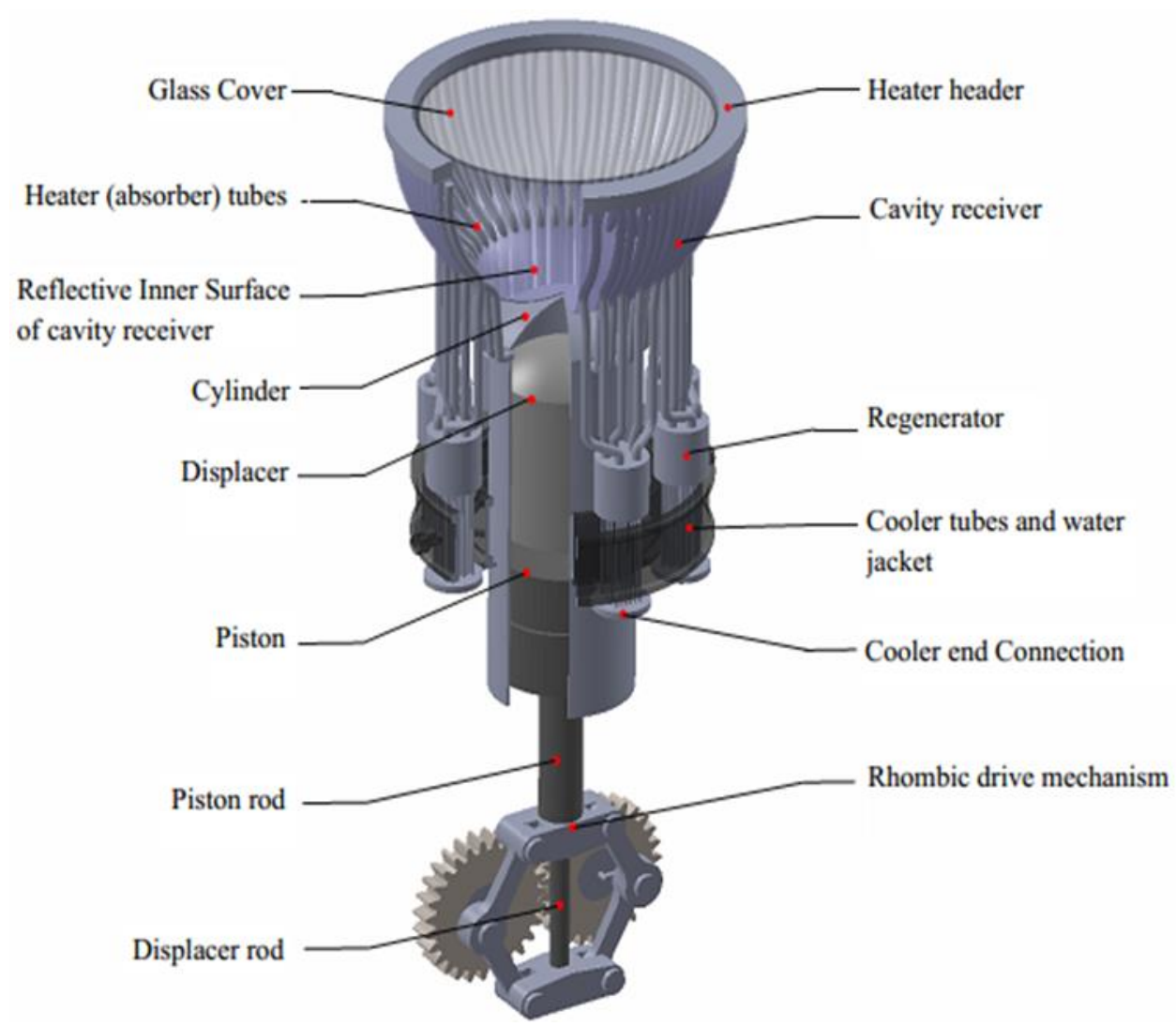

Fig. 13. Isometric view of solar Stirling engine

Table 2

Operating conditions of the current SDS engine

\begin{tabular}{ll}
\hline DNI & $1000 \mathrm{~W} / \mathrm{m}^{2}$ \\
Working fluid & Hydrogen \\
Engine speed & $3500 \mathrm{rpm}$ \\
Mean pressure of compression space & $6.92 \mathrm{MPa}$ \\
Metal-wall temperature of cooler tubes & $293 \mathrm{~K}$ \\
\hline
\end{tabular}

\section{Governing Equations}

In the present study, the flow is oscillatory, compressible and Newtonian. Hence, Unsteady Reynolds-Averaged Navier-Stokes (URANS) equations, besides the equation of state, are used to predict the thermal and the fluid flow fields in this model. Also, the radiative transfer equation (RTE) is used to account for the radiative mode of energy transfer between the receiver components. Here, the realizable $k-\varepsilon$ model with enhanced wall treatment for the near wall region is employed to estimate the turbulent viscosity. Among the different turbulent and transition models, it was proved to produce the most accurate predictions for the engine performance with a robust convergence for the solution [19]. Additionally, the regenerator is currently modelled using the local thermal nonequilibrium porous media approach. Among the several radiation models that are available in the ANYSY Fluent software, the Discrete Ordinates (DO) model is used in the current study. This is attributed to its capability of dealing with the complex geometries for different radiative participating media [40]. Furthermore, all types of surfaces, such as specular and diffusive reflectors, gray and nongray as well as semi-transparent ones, can be applied by the DO model [26]. More importantly, it is less expensive in terms of computational cost when applied with the dynamic meshes compared with 
other radiation models [40]. In short, this model, in particular, works across full range of conditions with high accuracy. The details of the all applied equations can be found in $[19,22]$.

\section{Methodology of CFD Simulation of Solar Stirling Engine}

The current simulation of the designed solar engine is conducted using the commercial CFD software ANSYS FLUENT, v14.5. The computational methodology and validation of the threedimensional CFD simulation is explained in the following subsections.

\subsection{Computational Domain and Grid}

The computational grid at the instance of zero crank angle $(\theta=0)$ is presented in Figure 14. It represents just one-eighth of the geometry is used as the computational domain in this simulation, to reduce the computational cost. In this solar engine, the domain generally consists of two main parts. The first one is the Stirling engine with its well-known components: compression and expansion spaces, displacer, appendix gap, regenerator, cooler and cooler-end connection in addition to the new heater. Hydrogen is the working fluid for these components. Whereas, the second part is the cavity receiver with its surfaces and fluid. Air is the working fluid in the cavity. The wall thickness for each component, except for displacer, is not taken into consideration. ANSYS DesignModeller is used for constructing the geometry while ANSYS Meshing is utilized to generate the computational grid. For the current simulation, some aspects should be followed to develop the grid that achieves an accurate and converged solution [19]. While, the different engine components are meshed using hexahedral elements, the tetrahedral ones are used to develop the grid in cavity receiver. This is conducted to avoid the complexity of creating a reasonable quality grid for the complicated geometries like the hemisphere. Additionally, a careful refinement is created around the heater tubes and near the different surfaces of the receiver, as illustrated from Figure 14.

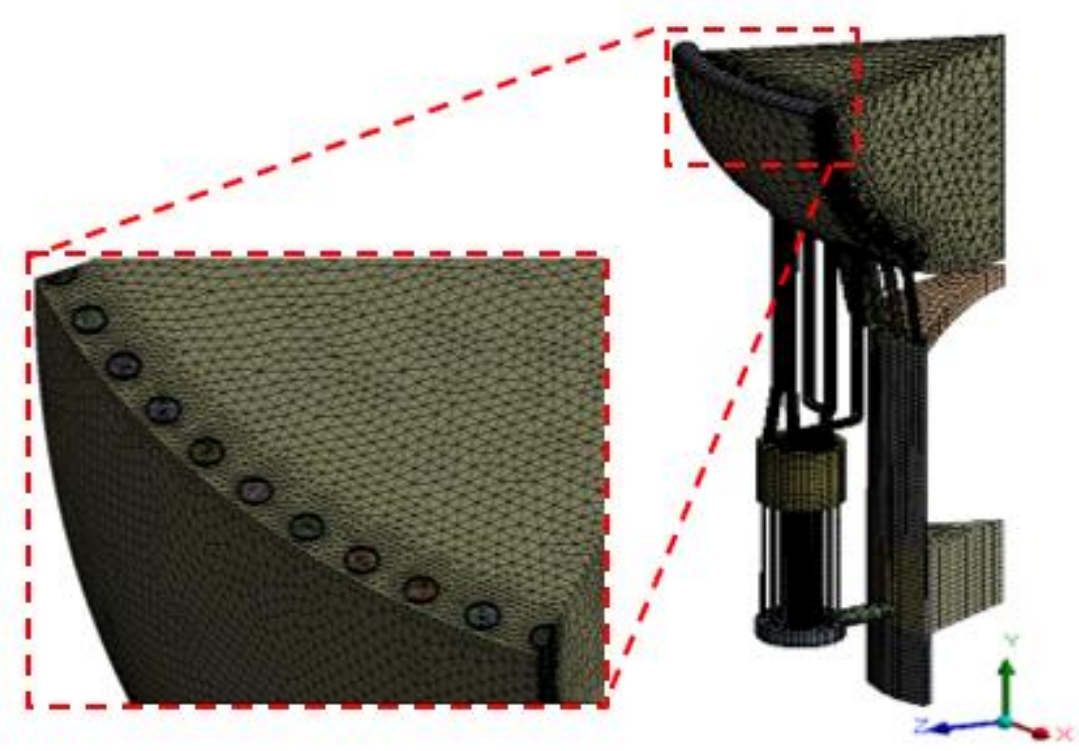

Fig. 14. Computational grid (number of cells is scaled down by $75 \%$ ) 


\subsection{Boundary and Initial Conditions}

Periodic boundary conditions are applied to the faces in the azimuthal direction since only oneeighth of the physical domain is modelled. No-slip boundary conditions are applied to all walls. As clarified from the operating conditions presented in Table 2, the temperatures of the different engine walls, except that of the cooler tubes, have not been given. Setting up these temperatures as boundary conditions is a crucial step in the CFD simulation of the engine. Accordingly, the walls temperatures should be assumed, but, under specific constraints. The technique of the assumptions was summarized by El-Ghafour et al., [20]. Accordingly, the representation and temperature values of the different walls that are applied in the current simulation are illustrated in Figure 15 and Table 3. The interior walls of the displacer are treated as adiabatic, while the piston walls are assumed isothermal at $305 \mathrm{~K}$. A linear temperature distribution is applied for the walls of the other parts.

\section{Table 3}

Temperature values of different walls of solar Stirling engine

\begin{tabular}{ll}
\hline Wall Name & Temperature $(\mathrm{K})$ \\
\hline EW1 & 905 \\
EW2 & 860 \\
CW & 325 \\
H3 & 1035 \\
H4 & 995 \\
C1 & 318 \\
C2 & 293 \\
C3 & 311 \\
\hline
\end{tabular}

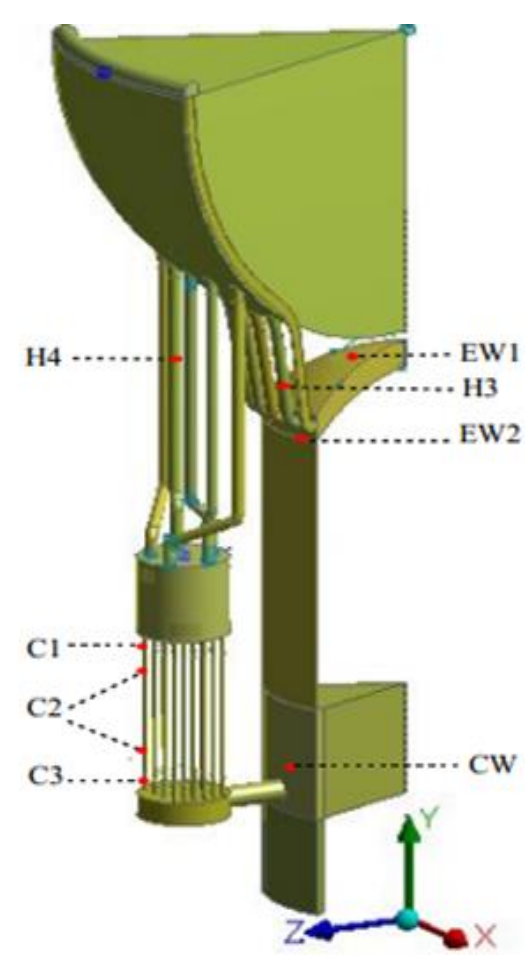

Fig. 15. Representation of different wall names of solar Stirling engine 
Here, the temperature of the heater walls is unknown. It is calculated during the simulation from the heat interaction between the cavity receiver components under the effect of the concentrated solar irradiance entering from the aperture (input heat flux). The receiver surface is set as an adiabatic wall with an internal reflectance of 0.94 . Whereas, the glass cover is considered as a semitransparent wall that allows the concentrated solar irradiance to enter the receiver domain. $A$ refractive index of 1 is applied for this wall. A natural convection and radiation boundary conditions is applied to the external side of the glass cover with a free stream temperature of $30^{\circ} \mathrm{C}$, a convective heat transfer coefficient of $15 \mathrm{~W} /\left(\mathrm{m}^{2} \mathrm{~K}\right)$ and an emissivity of 1.0. These proposed conditions enable estimating the natural convection and radiation losses from the receiver cover in a simple manner. For the current calculation, the cycle starts at $\theta=0$ and a pressure of $5.7 \mathrm{MPa}$.

\subsection{Solution Scheme}

The governing equations are discretized and solved sequentially using FLUENT, a finite volumebased solver. Transient, pressure-based, segregated SIMPLEC solver with absolute velocity formulation are the settings for the solution of current simulation. An uncoupled, gray radiation DO model is employed. The least squares method has been employed for computing the gradients of the transport quantities on the faces of the cell boundaries. The other spatial discretization methods in the simulations are standard for pressure term, and second-order upwind for continuity, momentum, energy, turbulence and RTE transport equations. The under-relaxation factors of pressure, momentum and RTE are set as $0.3,0.7$ and 1.0, respectively. Whereas an under-relaxation factor of 0.9 is applied for density, energy and turbulence quantities. First-order implicit formulation is applied for discretizing the temporal derivatives. The realizable $k-\varepsilon$ model with enhanced wall treatment is used with all default settings given in FLUENT 14.5. The concentrated irradiance and the directions of the corresponding rays at the receiver aperture are obtained from the optical simulation using the SolTRACE software, as mentioned earlier. Afterwards, these data are input into the CFD simulation via a 2D discrete Profile. The thermophysical properties (viscosity, specific heat and thermal conductivity) of hydrogen are taken to be temperature dependent. Whereas, the air, the cavity fluid, is considered incompressible ideal gas with constant thermophysical properties. The default values of the viscosity, thermal conductivity and specific heat of $1.7894 \times 10-5 \mathrm{~kg} /(\mathrm{m} . \mathrm{s}), 0.0242 \mathrm{~W} /(\mathrm{m} . \mathrm{K})$ and $1,006.43 \mathrm{~J} /(\mathrm{kg} . \mathrm{K})$ are used. Furthermore, it is considered a radiation participating media with zero absorption and scattering coefficients.

Several techniques can be followed for speeding up the convergence of the calculation, as documented in the previous work [19]. The details of implementing the reciprocating motion of the piston and the displacer and, consequently, the moving and deforming volumes were also presented in Ref. [19]. In the DO model, the RTE solution is independent of angular discretization parameters. Generally, the angular space is divided into $\mathrm{N}_{\theta} \mathrm{xN}$, control angles. The theta divisions $\left(\mathrm{N}_{\theta}\right)$ and phi divisions $\left(\mathrm{N}_{\phi}\right)$ are further subdivided by pixels. Therefore, these parameters, number of divisions and pixels, control the accuracy of the RTE solution. A pixelation of $3 \times 3$ is applied in the current study as it is recommended for problems that involves periodic and semi-transparent boundaries [41]. On the other hand, the specification of the number of divisions needs an independency study. Hence, the angular discretization and the spatial discretization (grid) independency studies are conducted to achieve a convergent and accurate solution in reasonable computational time. Moghimi et al., [40] specified the optimal method of conducting the spatial and angular discretization studies in this case. Firstly, a grid independence study of the coarsest control angles should be performed. After determining the suitable grid, an angular discretization study is then conducted. Here, the absorbed heat rate by the working fluid of the solar engine is tested for reaching the independence conditions. 
Accordingly, three different grid densities of 3.7 million, 4.0 million and 4.6 million cells are investigated at a constant number of divisions of $2 \times 2$. From this independency study, it is found that the deviation in the absorbed heat rate between the medium and fine grids does not exceed $1.5 \%$. Hence, the grid density of 4.0 million cells is adopted. In the same manner, three number of divisions of $2 \times 2,4 \times 4$ and $5 \times 5$ are tested at the grid density of 4.0. This independency study leads to select the medium number of divisions $(4 \times 4)$. Finally, a time step size independency test is conducted by investigating three-time step sizes of $6.1 \times 10^{-5} \mathrm{~s}, 4.285 \times 10^{-5} \mathrm{~s}$ and $3.06 \times 10^{-5} \mathrm{~s}$. According to this test, the time step size of $4.285 \times 10^{-5} \mathrm{~s}$ is adopted.

Due to the transient nature of this case, the convergence of the simulation is based on two criteria. The first one is the residuals of the transport equations. For each cycle, it is set at $1 \times 10-6$ for energy and DO equations, and $1 \times 10-3$ for the rest of the equations. While, monitoring some selected quantities for verifying the attaining of the cyclic steady state solution is the second convergence criterion. The average gas temperature variation of the subdomains is monitored for this purpose. The deviation in these values should be less than $1 \%$ in two subsequent cycles to reach the cyclic steady state. For each simulation, about 7 cycles are needed for the solution to become cyclic, and each cycle takes about $37 \mathrm{~h}$ on a Core i7-6700 acer CPU, 3.4 GHz processor with $16 \mathrm{~GB}$ dynamic memory.

\subsection{Model Validation}

In order to validate the current CFD model, a comparison of the predicted and the experimental results [23] of the GPU-3 Stirling engine is conducted. The comparison is based on the indicated power only [19]. Figure 16 displays the validation of the power results at the maximum and minimum operating pressures of 6.92 and $2.76 \mathrm{MPa}$, respectively. The comparison indicates that the current CFD results has shown a close agreement with the experimental results over the operating range.

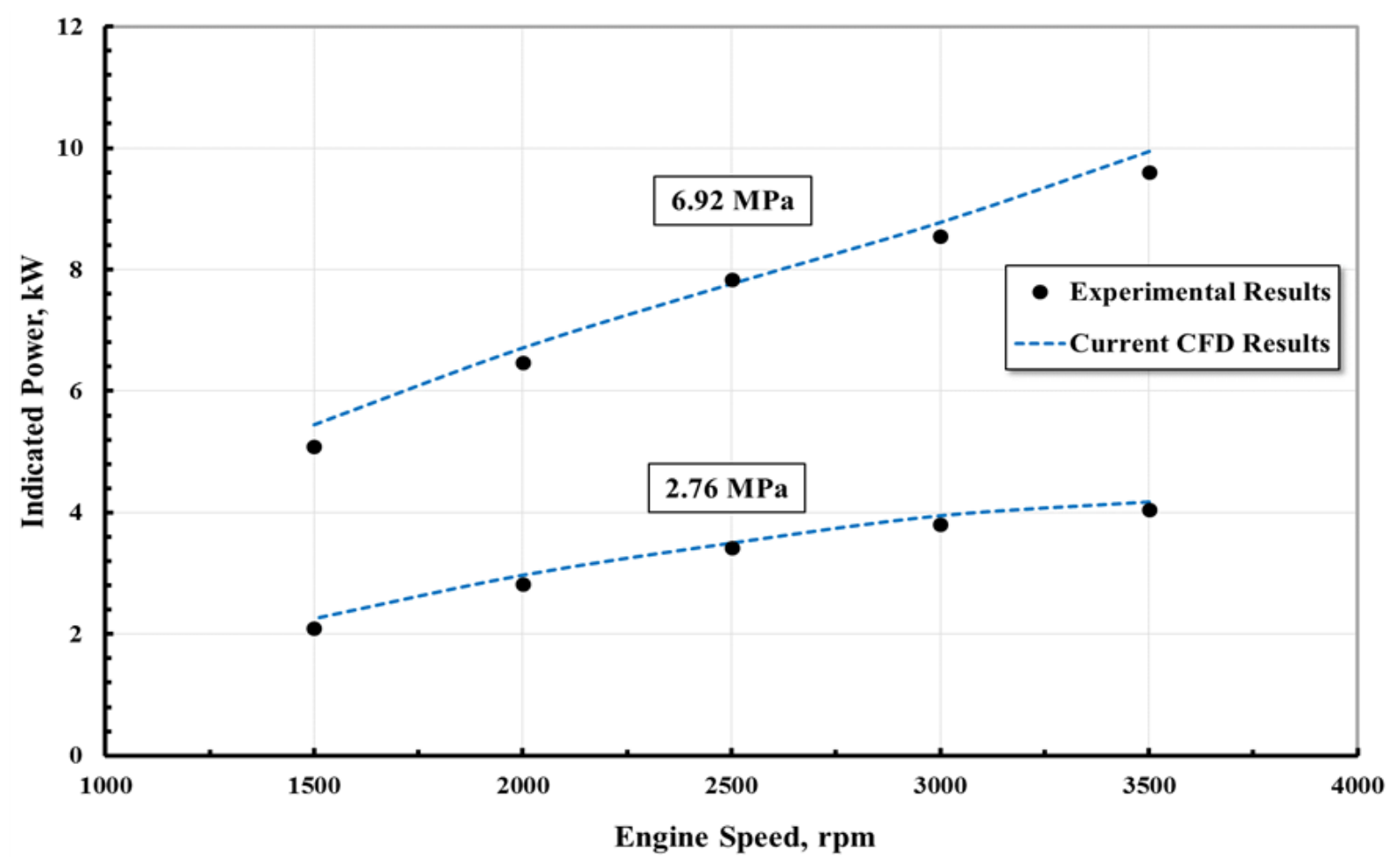

Fig. 16. Comparison of indicated power of GPU-3 Stirling engine between CFD and experimental results 


\section{Results and Discussion}

The optical simulation of the solar dish and receiver aperture is conducted under the standard design DNI value of $1000 \mathrm{~W} / \mathrm{m} 2$. The boundary irradiance distribution applied on the receiver aperture located at $5.4 \mathrm{~cm}$ from the focal plane of the 68 facets parabolic dish concentrator is illustrated in Figure 17.

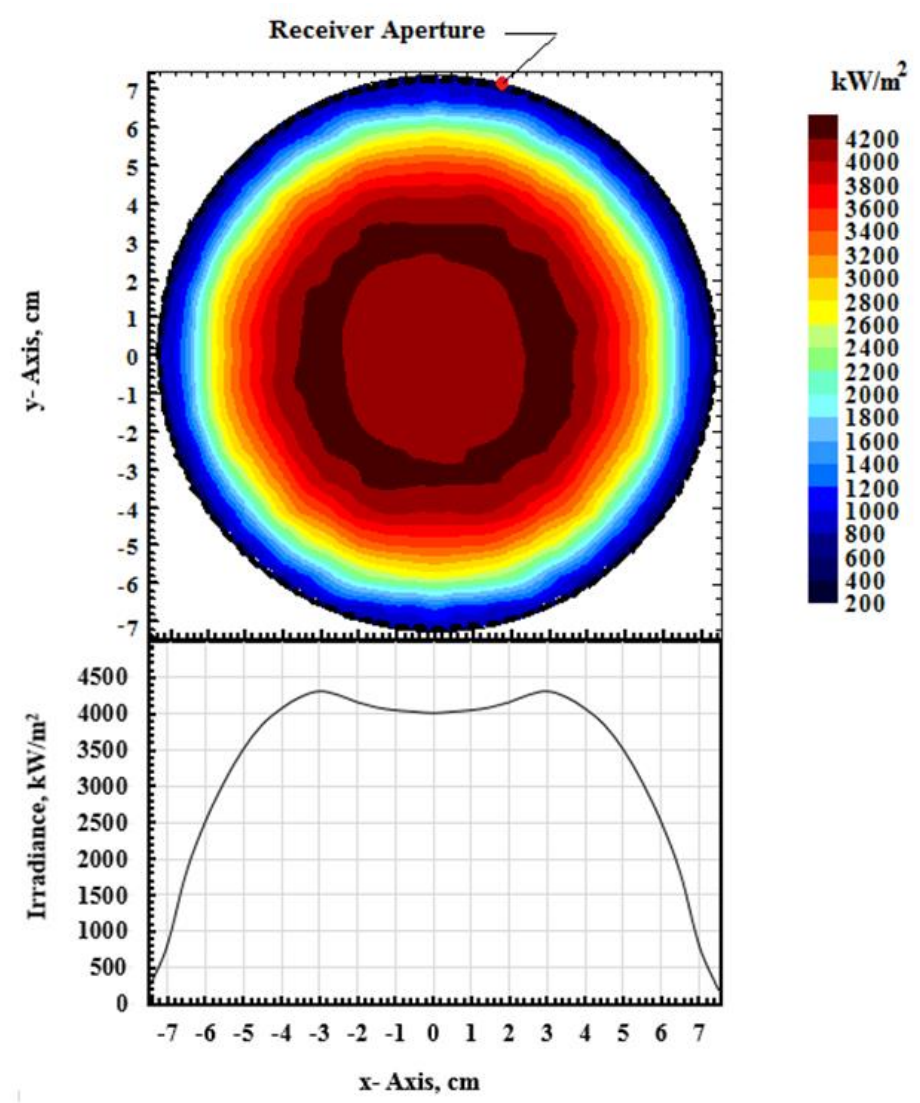

Fig. 17. Map of irradiance contours with spatial distribution in $\mathrm{x}$-direction on receiver aperture of designed SDS engine

During the cycle, by applying boundary irradiance distribution on the solar Stirlig engine, a nearly uniform temperature distribution of the heater tubes is achieved. This noticeably approaches isothermal heater tubes surfaces, as can be observed in Figure 18. Interestingly, the maximum temperature difference over the heater tubes surfaces during the whole cycle does not exceed $46 \mathrm{~K}$. Whereas, the corresponding value of this difference reaches about $130 \mathrm{~K}$ for the Eurodish SDS commercial unit [17]. This indicates the high degree of temperature distribution uniformity and, consequently, the effectivity of the current design. 


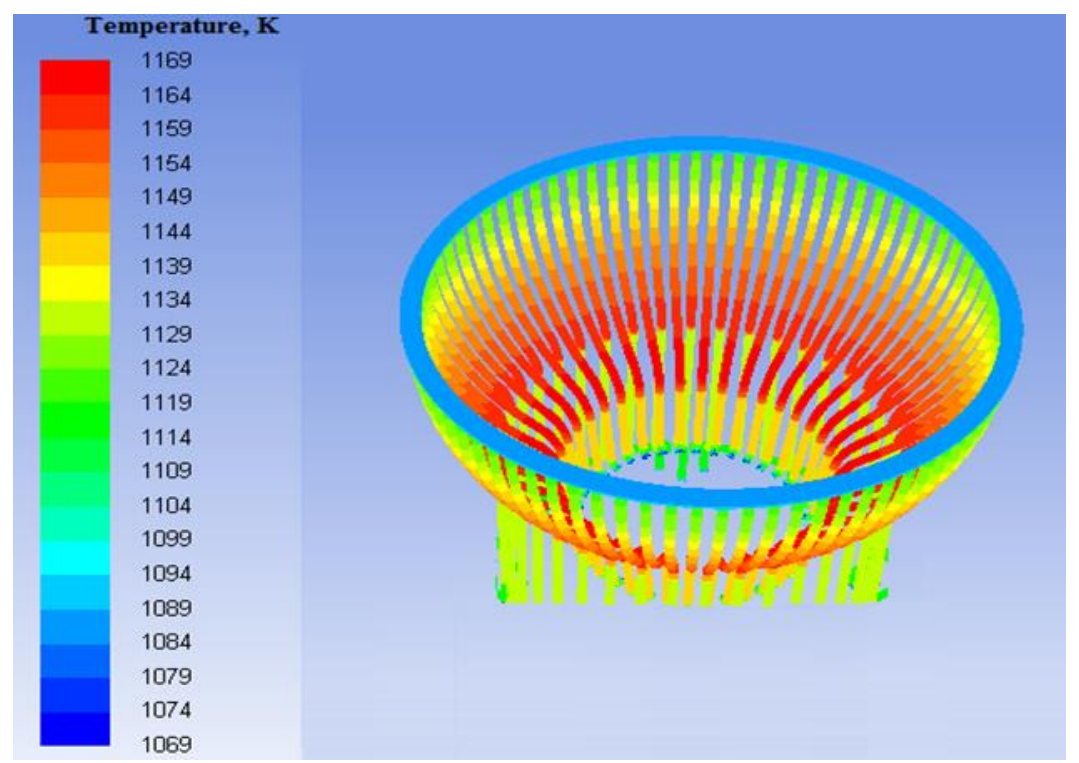

Fig. 18. Temperature distribution of the heater tubes of the designed solar Stirling engine at $\theta=135$

Figure 19 illustrates the instantaneous variations of the absorbed heat rate by the working fluid within the heater. From this figure, the cyclic rate of heat absorption in the heater can be calculated by integrating the instantaneous heat rate over the cycle [20].

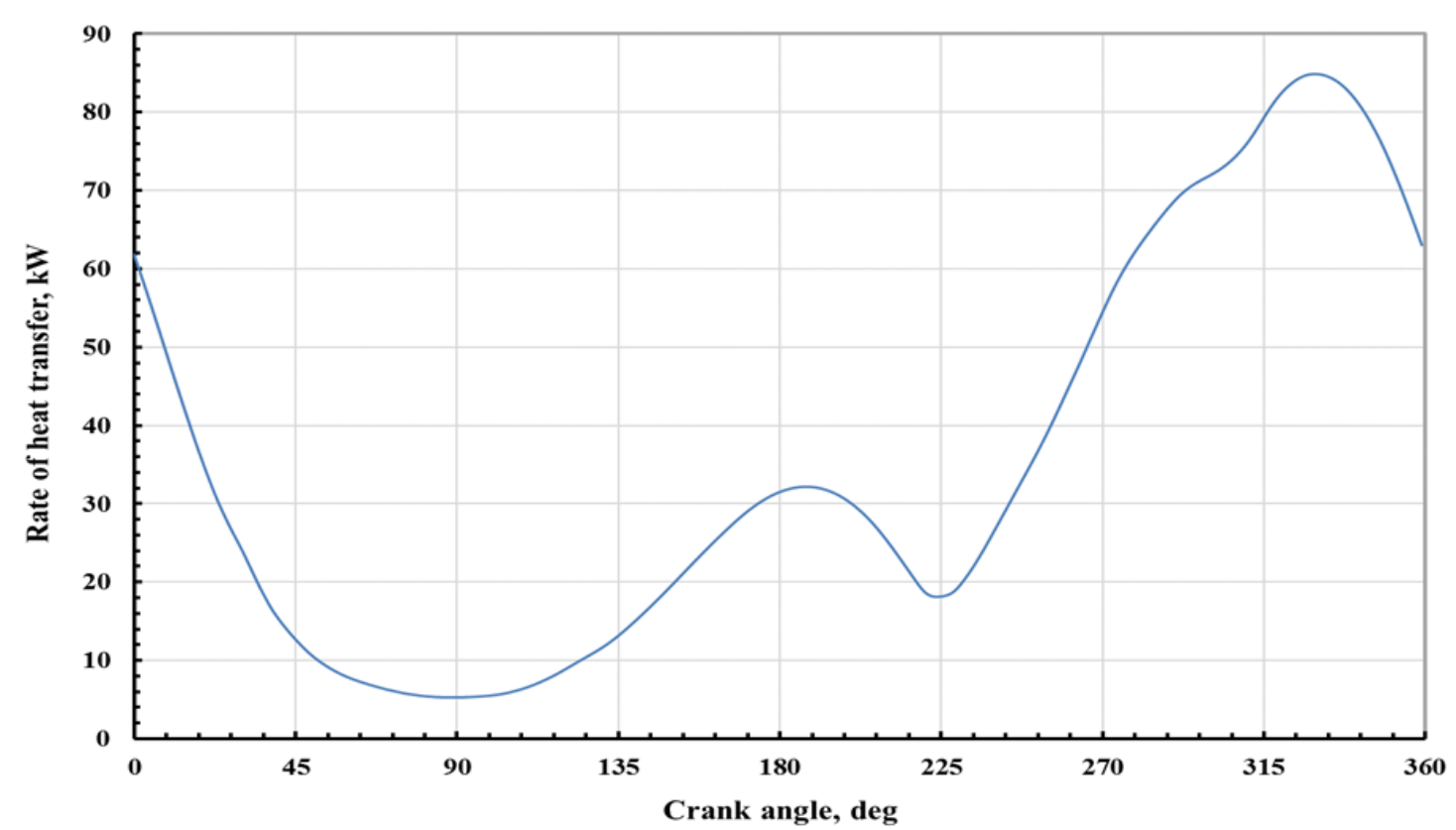

Fig. 19. Instantaneous absorbed heat rate by working fluid within heater as a function of crank angle

The $p$ - $V$ diagram of the compression and expansion spaces is shown in Figure 20. From this figure, the indicated power of the solar Stirling engine can be predicted by multiplying the integration of the enclosed area of $p-V$ diagrams for the working spaces by operating speed [20].

According to the data presented in this section, the losses and the efficiency of each component can be calculated. The optical efficiency of the solar concentration process, $\eta_{\text {con, }}$ is defined as the ratio of the energy intercepted by the receiver aperture to the energy incident on the dish concentrator. Whereas the ratio of the net power output to the added heat rate in the heater can be 
referred as the thermal efficiency of Stirling engine. For the current design, the optical efficiency is $90.83 \%$, while, the absorption efficiency of the receiver is $89.74 \%$. The thermal efficiency of the Stirling engine is estimated as 38.92\%. Accordingly, the overall thermal efficiency of the designed SDS engine is about $31.8 \%$. An energy balance representation for the SDS engine is illustrated in Figure 21.

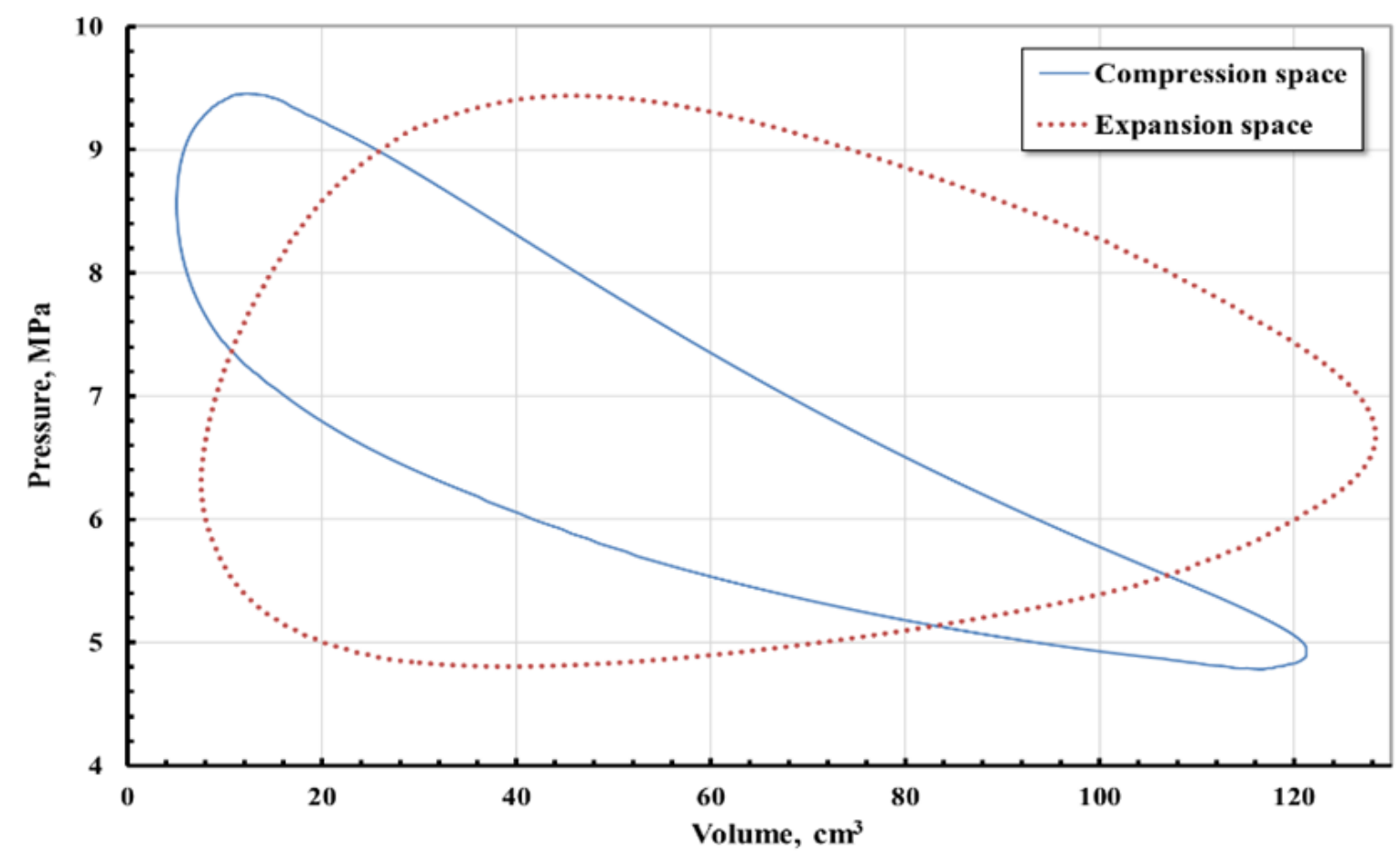

Fig. 20. $\mathrm{p}-\mathrm{V}$ diagrams of the compression and expansion spaces of the designed solar Stirling engine

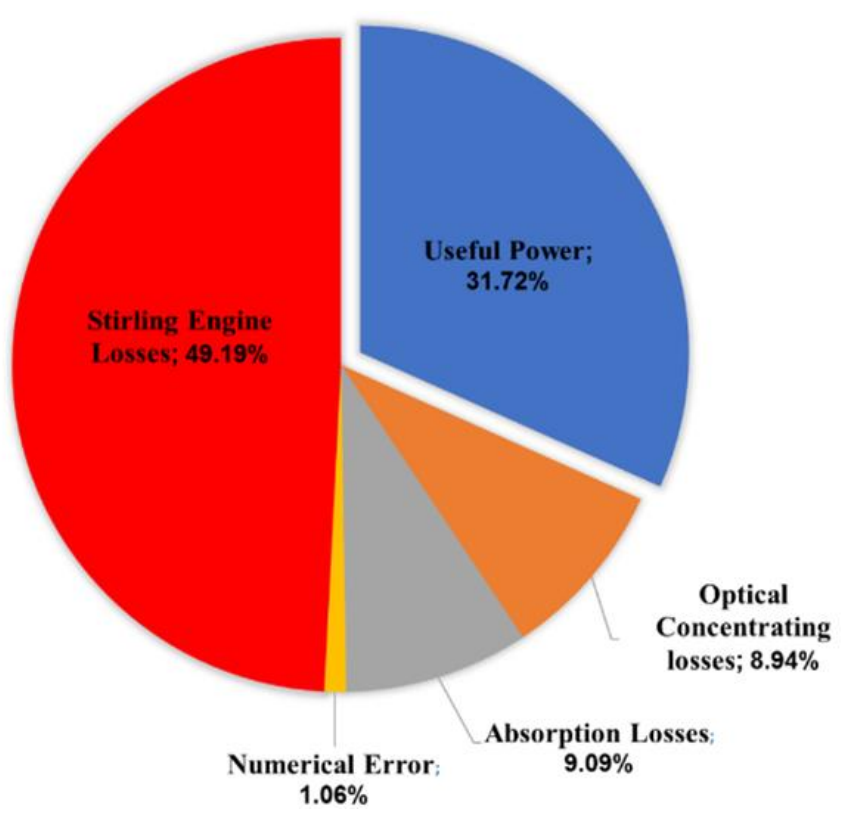

Fig. 21. Energy balance of the designed SDS engine 


\section{Conclusion}

Design and simulation of a SDS engine is currently performed. The design starts with the GPU-3 Stirling engine. The design is conducted through three subsequent phases. Firstly, several parabolic dishes with different rim angles and number of facets are investigated to optimally design the dish concentrator. Secondly, different relative positions of the receiver aperture to the dish focal plane are tested to reach the optimal position. The best compromise between the uniformity of the irradiance distribution at the aperture and the optical concentration ratio identifies the optimal design value. The optical simulation of the solar concentration process is carried out using SolTRACE software. Finally, an optimal design for a cavity receiver that involves a new structure of the heater tubes is performed. Three shapes of the cavity receiver are examined through a CFD simulation. The chosen shape is a trade-off between the optical absorbing rate and the pumping loss. Throughout the design phases, the following remarks are concluded

i. The use of the multi-facet parabolic dish leads to displacing the peak irradiance zone from the center towards the borders of the receiver aperture compared with the single continuous surface dish. Furthermore, it enhances the degree of irradiance distribution uniformity at the receiver aperture. Also, it results in an asymmetric distribution in the spatial directions.

ii. The number of facets with a proper alignment can be utilized as a control method for the degree of uniformity and to achieve the local peak irradiance at the desired location.

iii. A more uniform irradiance distribution is observed with the movement of the receiver backward relative to the focal plane. Meanwhile, the distance of the movement should be limited to avoid a large spillage loss and, consequently, a significant reduction in optical concentration ratio.

iv. The efficient design of the cavity receiver along with the heater tubes homogenizes the heat flux distribution on the heater tubes and, consequently, approaches the isothermal heater walls. This has been achieved by the utilization of a hemisphere cavity receiver with the following characteristics: a highly reflective inner surface, a fused silica glass cover and a suitable arrangement of the heater tubes that covered by a hightemperature selective coating.

v. Having finished the design, a comprehensive energy analysis of the designed SDS engine is carried out. The designed solar Stirling engine is operated at a pressure of $6.92 \mathrm{MPa}$ and speed of $3500 \mathrm{rpm}$ with hydrogen as the working fluid. The overall thermal efficiency of the designed solar Dish-Stirling engine is about $31.8 \%$ at a DNI of 1000 $\mathrm{W} / \mathrm{m} 2$.

\section{References}

[1] Rapier, Robert. "Fossil Fuels Still Supply 84 Percent Of World Energy - And Other Eye Openers From BP's Annual Review." (June, 2020). [Online]. https://www.forbes.com/sites/rrapier/bp-review-new-highs-in-global-energyconsumption-and-carbon-emissions-in-2019/

[2] Kulichenko, N., \& Khanna, A. (2013). Development of Local Supply Chain: The Missing Link for Concentrated Solar Power Projects in India (Vol 1). Energy Sector Management Assistance Program (ESMAP), The World Bank, Washington, DC.

[3] International Renewable Energy Agency (IRENA), "Global Energy Transportation." (2018). https://www.irena.org

[4] Kalogirou, Soteris A. "Progress in energy and combustion science." Prog. Ener. Combust. Sci 30 (2004): $231-295$. https://doi.org/10.1016/j.pecs.2004.02.001 
[5] Abbas, M., B. Boumeddane, N. Said, and A. Chikouche. "Techno economic evaluation of solar Dish Stirling system for stand alone electricity generation in Algeria." Journal of Engineering and Applied Sciences 4, no. 4 (2009): 258267.

[6] Behar, Omar, Abdallah Khellaf, and Kamal Mohammedi. "A review of studies on central receiver solar thermal power plants." Renewable and sustainable energy reviews 23 (2013): 12-39. https://doi.org/10.1016/i.rser.2013.02.017

[7] Günther, Matthias, and Reza Shahbazfar. "Advanced CSP Teaching Materials: Chapter 7 Solar Dish Technology." EnerMENA, DLR (2016).

[8] Barreto, Germilly, and Paulo Canhoto. "Modelling of a Stirling engine with parabolic dish for thermal to electric conversion of solar energy." Energy Conversion and Management 132 (2017): 119-135. https://doi.org/10.1016/i.enconman.2016.11.011

[9] Letcher, Trevor M. "Future energy: improved, sustainable and clean options for our planet/edited by Trevor M. Letcher." (2008).

[10] Bakos, G. C., and Ch Antoniades. "Techno-economic appraisal of a dish/stirling solar power plant in Greece based on an innovative solar concentrator formed by elastic film." Renewable energy 60 (2013): $446-453$. https://doi.org/10.1016/i.renene.2013.05.031

[11] Arora, Rajesh, S. C. Kaushik, Raj Kumar, and Ranjana Arora. "Multi-objective thermo-economic optimization of solar parabolic dish Stirling heat engine with regenerative losses using NSGA-II and decision making." International Journal of Electrical Power \& Energy Systems 74 (2016): 25-35. https://doi.org/10.1016/j.ijepes.2015.07.010

[12] Yaqi, Li, He Yaling, and Wang Weiwei. "Optimization of solar-powered Stirling heat engine with finite-time thermodynamics." Renewable energy 36, no. 1 (2011): 421-427. https://doi.org/10.1016/i.renene.2010.06.037

[13] Ahmadi, Mohammad Hossein, Hoseyn Sayyaadi, Saeed Dehghani, and Hadi Hosseinzade. "Designing a solar powered Stirling heat engine based on multiple criteria: maximized thermal efficiency and power." Energy Conversion and Management 75 (2013): 282-291. https://doi.org/10.1016/i.enconman.2013.06.025

[14] Li, Mingzhen, and Jinzhong Dong. "Modeling and simulation of solar dish-Stirling systems." In 2012 Asia-Pacific Power and Energy Engineering Conference, pp. 1-7. IEEE, 2012. https://doi.org/10.1109/APPEEC.2012.6307165

[15] Beltrán-Chacon, Ricardo, Daniel Leal-Chavez, D. Sauceda, Manuel Pellegrini-Cervantes, and Mónica Borunda. "Design and analysis of a dead volume control for a solar Stirling engine with induction generator." Energy 93 (2015): 2593-2603. https://doi.org/10.1016/i.energy.2015.09.046

[16] Kadri, Y., and H. Hadj Abdallah. "Performance evaluation of a stand-alone solar dish Stirling system for power generation suitable for off-grid rural electrification." Energy Conversion and Management 129 (2016): 140-156. https://doi.org/10.1016/j.enconman.2016.10.024

[17] Nepveu, Francois, Alain Ferriere, and Francoise Bataille. "Thermal model of a dish/Stirling systems." Solar Energy 83, no. 1 (2009): 81-89. https://doi.org/10.1016/j.solener.2008.07.008

[18] Yan, J., Y. D. Peng, Z. R. Cheng, F. M. Liu, and X. H. Tang. "Design and implementation of a $38 \mathrm{~kW}$ dish-Stirling concentrated solar power system." In IOP Conference Series: Earth and Environmental Science, vol. 93, no. 1, p. 012052. IOP Publishing, 2017. https://doi.org/10.1088/1755-1315/93/1/012052

[19] El-Ghafour, S. A., M. El-Ghandour, and N. N. Mikhael. "Three-dimensional computational fluid dynamics simulation of stirling engine." Energy conversion and management $180 \quad$ (2019): 533-549. https://doi.org/10.1016/j.enconman.2018.10.103

[20] El-Ghafour, Sherihan, Nady Mikhael, and Mohamed El-Ghandour. "Energy and Exergy Analyses of Stirling Engine using CFD Approach." Journal of Advanced Research in Fluid Mechanics and Thermal Sciences 77, no. 1 (2021): 100123. https://doi.org/10.37934/arfmts.77.1.100123

[21] Alfarawi, S., R. Al-Dadah, and S. Mahmoud. "Influence of phase angle and dead volume on gamma-type Stirling engine power using CFD simulation." Energy Conversion and Management 124 (2016): 130-140. https://doi.org/10.1016/i.enconman.2016.07.016

[22] El-Ghafour, S. "Design and Computational Fluid Dynamics Simulation of a Solar Stirling Engine." PhD diss., Ph. D. Dissertation, University of Port Said, Port Said, Egypt (2018).

[23] Thieme, Lanny G. "High-power baseline and motoring test results for the GPU-3 Stirling engine." (1981).

[24] Hafez, A. Z., Ahmed Soliman, K. A. El-Metwally, and I. M. Ismail. "Solar parabolic dish Stirling engine system design, simulation, and thermal analysis." Energy conversion and management 126 (2016): 60-75. https://doi.org/10.1016/j.enconman.2016.07.067

[25] Thakkar, Vanita, Ankush Doshi, and Akshaykumar Rana. "Performance analysis methodology for parabolic dish solar concentrators for process heating using thermic fluid." Journal of Mechanical and Civil Engineering 12, no. 1 (2015): 101-114 
[26] Li, Zhigang, Dawei Tang, Jinglong Du, and Tie Li. "Study on the radiation flux and temperature distributions of the concentrator-receiver system in a solar dish/Stirling power facility." Applied Thermal Engineering 31, no. 10 (2011): 1780-1789. https://doi.org/10.1016/i.applthermaleng.2011.02.023

[27] Zanganeh, Giv, Roman Bader, Andrea Pedretti, Marco Pedretti, and Aldo Steinfeld. "A solar dish concentrator based on ellipsoidal polyester membrane facets." Solar Energy 86, no. 1 (2012): 40-47. https://doi.org/10.1016/i.solener.2011.09.001

[28] Pavlović, Saša R., Velimir P. Stefanović, and Suad H. Suljković. "Optical modeling of a solar dish thermal concentrator based on square flat facets." Thermal Science 18, no. 3 (2014): 989-998. https://doi.org/10.2298/TSCI1403989P

[29] Le Roux, Willem Gabriel, Tunde Bello-Ochende, and Josua P. Meyer. "The efficiency of an open-cavity tubular solar receiver for a small-scale solar thermal Brayton cycle." Energy Conversion and Management 84 (2014): 457-470. https://doi.org/10.1016/i.enconman.2014.04.048

[30] Dunn, Rebecca, Keith Lovegrove, Greg Burgess, and John Pye. "An experimental study of ammonia receiver geometries for dish concentrators." Journal of Solar Energy Engineering 134, no. 4 (2012). https://doi.org/10.1115/1.4006891

[31] Sup, Billy Anak, Mohd Farid Zainudin, Tanti Zanariah Shamsir Ali, Rosli Abu Bakar, and Gan Leong Ming. "Effect of rim angle to the flux distribution diameter in solar parabolic dish collector." Energy procedia 68 (2015): $45-52$. https://doi.org/10.1016/j.egypro.2015.03.231

[32] Kaushika, N. D., and K. S. Reddy. "Performance of a low cost solar paraboloidal dish steam generating system." Energy conversion and management 41, no. 7 (2000): 713-726. https://doi.org/10.1016/S01968904(99)00133-8

[33] Riveros-Rosas, David, Marcelino Sánchez-González, Camilo A. Arancibia-Bulnes, and Claudio A. Estrada. "Influence of the size of facets on point focus solar concentrators." Renewable energy 36, no. 3 (2011): 966-970. https://doi.org/10.1016/i.renene.2010.08.038

[34] Perez-Enciso, Ricardo, Alessandro Gallo, David Riveros-Rosas, Edward Fuentealba-Vidal, and Carlos Perez-Rábago. "A simple method to achieve a uniform flux distribution in a multi-faceted point focus concentrator." Renewable Energy 93 (2016): 115-124. https://doi.org/10.1016/i.renene.2016.02.069

[35] Shuai, Yong, Xinlin Xia, and Heping Tan. "Numerical simulation and experiment research of radiation performance in a dish solar collector system." Frontiers of Energy and Power Engineering in China 4, no. 4 (2010): $488-495$. https://doi.org/10.1007/s11708-010-0007-z

[36] FRASER, PR. "Stirling Dish System Performance Prediction Model, UNIVERSITY OF WISCONSIN-MADISON." MASTER OF SCIENCE (2008).

[37] Fedawy, Mostafa, Shereen Mostafa Ali, and Tarek Abdolkader. "Efficiency Enhancement of GaAs Solar Cell using Si3N4 Anti-reflection Coating." Journal of Advanced Research in Materials Science 42: 1-7.

[38] Shantia, Alireza, Hamid Kayal, Wolfgang Streicher, and Solar Island. "Modelling of Heat Transfer in a Trapezoidal Cavity Receiver for a Linear Fresnel Solar Collector with Fixed/Narrow Reflectors." (2015). https://doi.org/10.18086/eurosun.2014.16.21

[39] Mao, Qianjun, Yong Shuai, and Yuan Yuan. "Study on radiation flux of the receiver with a parabolic solar concentrator system." Energy Conversion and Management 84 (2014): 1-6. https://doi.org/10.1016/i.enconman.2014.03.083

[40] Moghimi, M. A., K. J. Craig, and Josua P. Meyer. "A novel computational approach to combine the optical and thermal modelling of Linear Fresnel Collectors using the finite volume method." Solar Energy 116 (2015): $407-427$. https://doi.org/10.1016/i.solener.2015.04.014

[41] Ben-Mansour, R., A. Abuelyamen, and Esmail MA Mokheimer. "CFD analysis of radiation impact on Stirling engine performance." Energy conversion and management $152 \quad$ (2017): https://doi.org/10.1016/i.enconman.2017.09.056 